\title{
Estimation of the mass absorption cross section of the organic carbon component of aerosols in the Mexico City Metropolitan Area
}

\author{
J. C. Barnard ${ }^{1}$, R. Volkamer ${ }^{2}$, and E. I. Kassianov ${ }^{1}$ \\ ${ }^{1}$ Pacific Northwest National Laboratory, Richland, Washington, USA \\ ${ }^{2}$ University of Colorado, Boulder, Colorado, USA
}

Received: 20 February 2008 - Published in Atmos. Chem. Phys. Discuss.: 30 May 2008

Revised: 8 September 2008 - Accepted: 28 September 2008 - Published: 19 November 2008

\begin{abstract}
Data taken from the MCMA-2003 and the 2006 MILAGRO field campaigns are used to examine the absorption of solar radiation by the organic component of aerosols. Using irradiance data from a Multi-Filter Rotating Shadowband Radiometer (MFRSR) and an actinic flux spectroradiometer (SR), we derive aerosol single scattering albedo, $\varpi_{0, \lambda}$, as a function of wavelength, $\lambda$. We find that in the near-UV spectral range $(250$ to $400 \mathrm{~nm}) \varpi_{0, \lambda}$ is much lower compared to $\varpi_{0, \lambda}$ at $500 \mathrm{~nm}$ indicating enhanced absorption in the near-UV range. Absorption by elemental carbon, dust, or gas cannot account for this enhanced absorption leaving the organic carbon component of the aerosol $(\mathrm{OA})$ as the most likely absorber. We use data from a surface deployed Aerodyne Aerosol Mass Spectrometer (AMS) along with the inferred $\varpi_{0, \lambda}$ to estimate the Mass Absorption Cross section (MAC) for the organic aerosol. We find that the MAC is about $10.5 \mathrm{~m}^{2} / \mathrm{g}$ at $300 \mathrm{~nm}$ and falls close to zero at about $500 \mathrm{~nm}$; values that are roughly consistent with other estimates of organic aerosol MAC. These MAC values can be considered as "radiatively correct", because when used in radiative transfer calculations, the calculated irradiances/actinic fluxes match those measured at the wavelengths considered here. For an illustrative case study described here, we estimate that the light absorption by the "brown" (organic) carbonaceous aerosol can add about $40 \%$ to the light absorption of black carbon in Mexico City. This contribution will vary depending on the relative abundance of organic aerosol relative to black carbon. Furthermore, our analysis indicates that organic aerosol would slow down photochemistry by selectively scavenging the light reaching the ground at those wavelengths that drive photochemical
\end{abstract}

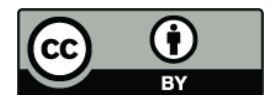

Correspondence to: J. C. Barnard (james.barnard@pnl.gov) reactions. Finally, satellite retrievals of trace gases that are used to infer emissions currently assume that the MAC of organic carbon is zero. For trace gases that are retrieved using wavelengths shorter then $420 \mathrm{~nm}$ (i.e. $\mathrm{SO}_{2}, \mathrm{HCHO}$, halogenoxides, $\mathrm{NO}_{2}$ ), the assumption of non-zero MAC values will induce an upward correction to the inferred emissions. This assumption will be particularly relevant in polluted urban atmospheres and areas of biomass burning where organic aerosols are particularly abundant.

\section{Introduction}

Atmospheric aerosols that contain carbon absorb considerable amounts of solar energy. This absorption influences the climate through direct and semi-direct aerosol forcing (IPCC, 2007; htpp://www.ipcc.ch). Although so-called black carbon (BC) is the most potent absorber over the solar spectrum (Bond and Bergstrom, 2006), attention has turned recently to "brown" organic carbon (Andreae and Gelencsér, 2006; Sun et al., 2007; Alexander et al., 2008, and references therein) as a source of significant absorption, particularly in the near-UV. The magnitude of the mass absorption cross-section (MAC, with units $\mathrm{m}^{2} / \mathrm{g}$ ) of organic carbon component of the aerosol, abbreviated here as OA, and its variation with wavelength, $\lambda$, are thought to follow this general framework: compared to $\mathrm{BC}$, the MAC of $\mathrm{OA}$ is very modest in the visible spectral region, but increases dramatically towards the near-UV spectral region. The details of this framework are still highly uncertain, and this uncertainty motivates this paper. Here we examine the spectral behavior of OA absorption and MAC in an urban area, the Mexico City Metropolitan Area (MCMA). The MCMA is an excellent place to study OA absorption because the

Published by Copernicus Publications on behalf of the European Geosciences Union. 
OA mass of the aerosol is quite large (55\% by mass; Salcedo et al., 2006). Furthermore, the relative humidity can be so small that the liquid water content of aerosols is not a major component of the aerosol mass (San Martini et al., 2006), and the high altitude of the MCMA diminishes scattering by gas molecules thus strengthening the aerosol absorption signature. In this study, we use data observed during the MCMA-2003 field campaign (Molina et al., 2007; http: $/ / \mathrm{mce} 2.0 \mathrm{rg} / \mathrm{fc} 03 / \mathrm{fc} 03 . \mathrm{html}$ ) at the so-called CENICA Supersite located in the southeast part of the MCMA. These data are supplemented by some data from the 2006 MILAGRO field campaign (http://www.eol.ucar.edu/projects/milagro).

That OA has the potential to absorb strongly in the nearUV has been recognized for many years (Jacobson, 1999, and references therein; Bond et al., 1999). Recently OA absorption has been studied in both laboratory and field studies, with a focus on the near-UV spectral region. In a pioneering laboratory/field study, Kirchstetter et al. (2004) analyzed numerous filter samples taken in the field containing aerosols of two distinct types: those formed in regions of biomass burning and those produced in areas with emissions from motor vehicles, including diesel trucks. They measured the "normalized light attenuation" in a wavelength range of approximately 300 to $1000 \mathrm{~nm}$, and they found that the wavelength dependence of light absorption is described approximately by a $\lambda^{-1}$ dependence for the motor vehicle aerosols, consistent with absorption by BC. (The exponent " 1 " in the power law dependence is called the absorption Ångström exponent, AAE.) On the other hand, the absorption from the biomass aerosol varied approximately as $\lambda^{-2}$ caused by strong light absorption below $600 \mathrm{~nm}$, attributed to strong OA absorption in this spectral range in addition to the $\mathrm{BC}$ absorption. Schnaiter et al. (2006) studied the absorption of OA aerosols generated in the laboratory by propane combustion. By changing the oxygen/carbon ratio $(\mathrm{O} / \mathrm{C})$ they could produce aerosols with a varying $\mathrm{OC} / \mathrm{TC}$ ratio $(\mathrm{TC}=$ total carbon, the sum of organic carbon, $\mathrm{OC}$, and $\mathrm{BC}$ ). As this ratio increased the AAE became larger in accord with Kirchstetter et al.'s (2004) analysis of field samples, although for large OC/TC ratios the AAE considerably exceeded 2 .

Large AAE in the presence of large OC/TC ratios were noted by Roden et al. (2006), who examined emissions from wood burning cook stoves; these emissions contained a mix of elemental carbon, EC, ${ }^{1}$ and OC. They found for the cooking fires in vigorous and gentle flaming modes, the AAE was about 1.3, close to the $\mathrm{BC}$ value of one, but as the fires entered a smoldering phase, the AAE increased substantially, indicating the presence of substantial amount of OC. Mass absorption cross sections measured

\footnotetext{
${ }^{1}$ The distinction between so-called black carbon and so-called elemental carbon is an important issue that has been discussed widely in the literature (Bond and Bergstrom, 2006; Andreae and Gelencsér, 2006). For the purposes of this paper, we take BC and EC concentrations to be equivalent, unless otherwise noted.
}

under conditions of large OC/TC ratios were about $1 \mathrm{~m}^{2} / \mathrm{g}$ or less (at $530 \mathrm{~nm}$ ) indicating the possibility of some OC absorption in the visible wavelength region.

Sun et al. (2007) analyzed the visible and ultraviolet absorption spectra of various organic compounds to develop MACs for combustion and humic-like organic aerosols. Their analysis indicated significant absorption in the nearUV with MAC exceeding $10 \mathrm{~m}^{2} / \mathrm{g}$ below $300 \mathrm{~nm}$ for combustion particles.

Bergstrom et al. (2007) analyzed data from five field campaigns to summarize the spectral absorption of aerosols, as represented by aerosol absorption optical depth, $\tau_{\mathrm{abs}, \lambda}$, defined as $\left(1-\varpi_{0, \lambda}\right) \tau_{\mathrm{ext}, \lambda}$, where $\tau_{\mathrm{ext}, \lambda}$ is the usual extinction aerosol optical thickness. This paper also provided spectra of $\varpi_{0, \lambda}$. The value of the AAE depended on the type of aerosol being lowest $(\leq 1)$ for urban pollution, and extending up to approximately 3 for aerosols with a significant dust component. The spectra of $\varpi_{0, \lambda}$ showed a decrease of $\varpi_{0, \lambda}$ with increasing $\lambda$, except in the presence of large amounts of dust, in which case an opposite trend was observed in the near-UV and visible wavelength ranges. This trend will be discussed in Sect. 3.

As part of the INTEX-A field campaign (Singh et al., 2006), Clarke et al. (2007) measured the aerosol optical and chemical properties for pollution and biomass burning aerosols. They segregated OC into two fractions - refractory and volatile - depending upon whether the $\mathrm{OC}$ was volatile below $400^{\circ} \mathrm{C}$ or not. Of the TC mass, the so-called "RefractoryOC" (not volatile under $400^{\circ} \mathrm{C}$ ) was responsible for the bulk of the light absorption, with derived MACs of $0.63 \mathrm{~m}^{2} / \mathrm{g}$ at $470 \mathrm{~nm}$ and $0.09 \mathrm{~m}^{2} / \mathrm{g}$ at $530 \mathrm{~nm}$ suggesting that the some types of OC absorb preferentially at lower wavelengths. Clarke et al. (2007) noted that although the MAC of RefractoryOC was much less than that of BC $\left(7.5 \mathrm{~m}^{2} / \mathrm{g}\right.$ at $550 \mathrm{~nm}$, Bond and Bergstrom, 2006), the OC absorption could rival that of $\mathrm{BC}$ absorption at the lower wavelengths if the OC concentration was large enough. We note that the application of heat during aerosol measurements may encourage the formation of aerosol organic material of high molecular mass (Denkenberger et al., 2007). This alteration of chemical properties may induce changes to aerosol optical properties so that the observed optical properties may be different than the properties of unheated, ambient aerosols. However, it is difficult to assess quantitatively to what extent, if any, the mechanism proposed by Denkenberger et al. (2007) influences the results of Clarke et al. (2007).

Using a technique that is not applied often to atmospheric aerosols (high spatial resolution energy-loss spectroscopy), Alexander et al. (2008) have examined the optical properties of single brown carbon spheres that are embedded in the outflow from east Asia. They found that these spheres absorb significantly in the visible region, with increasing absorption in the near-UV spectral region. 
The literature above indicates that OA could be a significant absorber, and even equal or exceed the absorption of $\mathrm{BC}$ in certain wavelength regions, with implications for climate and photochemistry (Hoffer et al., 2006). The approach we take here differs from those described above in two important ways. First, we rely on an analysis of in situ measurements of solar irradiances, actinic flux, and OA mass. The use of irradiances and actinic fluxes to find MAC implies that the MAC are "radiatively correct" (Barnard et al., 2007; Schuster et al., 2005) meaning that, when the MAC are used in radiative transfer calculations, the calculated and measured irradiances agree. Second, the MACs so derived are appropriate for an atmospheric column rather than a point in the atmosphere and therefore partially bypass the issue of the representativeness of point measurements to larger scales.

\section{Methodology}

The methodology behind this work consists of four steps, summarized below, followed by additional explanation as needed. The four steps are:

1. Irradiance measurements from a Multi-Filter Rotating Shadowband Radiometer (MFRSR, Harrison et al., 1994) are used to find $\varpi_{0}$ at five discrete wavelengths, ranging from 415 to $870 \mathrm{~nm}$. Actinic flux measurements from a spectroradiometer (SR) are inverted to yield $\varpi_{0, \lambda}$ at $1-\mathrm{nm}$ or $5-\mathrm{nm}$ increments for wavelengths extending from 300 to $450 \mathrm{~nm}$. These values of $\varpi_{0, \lambda}$ are combined with either measured values of $\tau_{\mathrm{ext}, \lambda}$ or estimated values of the same to find $\tau_{\mathrm{abs}, \lambda}$ as a function of wavelength. Because the concentration of nitrogen dioxide $\left(\mathrm{NO}_{2}\right)$ and sulfur dioxide $\left(\mathrm{SO}_{2}\right)$ can be large in the MCMA, it is important to account for their gaseous absorption in this analysis. Measurements of $\mathrm{SO}_{2}$ and $\mathrm{NO}_{2}$ were performed by Long-path Differential Optical Absorption Spectroscopy (LP-DOAS, Volkamer et al., 2005).

2. The organic aerosol (OA) surface mass concentration, $\rho_{\mathrm{OA}}$, is measured with the Aerodyne Aerosol Mass Spectrometer (AMS; Jayne et al., 2000; Jimenez et al., 2003) that measures non-refractory components of the aerosol, for particles less than about $1 \mu \mathrm{m}$ in diameter. We note here the distinction between OC and OA mass, as described for example in Turpin and Lim (2001), where OC mass is the measured mass of carbon molecules associated with organic compounds, while $\mathrm{OA}$ is the mass of these compounds.

3. The surface concentrations of $\mathrm{NO}_{2}, \mathrm{SO}_{2}$, and $\rho_{\mathrm{OA}}$ are used in combination with aerosol mixing height information, $H$, to estimate $\mathrm{NO}_{2}$ and $\mathrm{SO}_{2}$ vertical column densities and the columnar OA mass concentration, $\rho_{\mathrm{OA}} H$.
4. An estimate of the MAC as a function of wavelength follows immediately:

$\operatorname{MAC}(\lambda)=\frac{\tau_{\mathrm{abs}, \lambda}-\tau_{\mathrm{abs}, \lambda, \text { other }}}{\rho_{\mathrm{OA}} H}$,

where $\tau_{\text {abs }, \lambda \text {.other }}$ is the absorption optical thickness for all other absorbers in the atmosphere including $\mathrm{NO}_{2}, \mathrm{SO}_{2}$, ozone, dust, and black carbon.

\subsection{Extracting $\varpi_{0, \lambda}$ from MFRSR and SR data}

In the first step, the MFRSR is a radiometer that measures the solar irradiance at six discrete wavelengths, 415, 500, $615,673,870$, and $940 \mathrm{~nm}$. For each wavelength, the diffuse and total components of the radiation are measured, and the direct component is inferred from these two measured components. Because of the shadowband design, the calibration for all components is the same, and ratios between the components are calibration independent. Using the direct beam irradiance, one can easily find $\tau_{\mathrm{ext}, \lambda}$ at all wavelengths except $940 \mathrm{~nm}$, where strong water vapor absorption occurs. For the MFRSR data in this study, we refer only to the five wavelengths uncontaminated by vapor absorption. The accuracy of these values has been shown to be $\sim 0.01$ for wavelengths $500 \mathrm{~nm}$ and above (Alexandrov et al., 2007; Michalsky et al., 2001).

The spectroradiometer measured the downwelling portion of the solar actinic flux (Volkamer et al., 2005, 2007b). Briefly, the radiation from the upper hemisphere of the instrument was collected by a diffuser-optic with almost uniform sensitivity for all angles of incidence within a solid angle of $2 \pi$ steradians. A Bentham DMc 150 double monochromator equipped with a tunable grating $(2400$ grooves $/ \mathrm{mm})$ was used for wavelength dispersion and a photomultiplier for photon detection. Spectra were recorded from 280 to $450 \mathrm{~nm}$ with a spectral band pass of $1 \mathrm{~nm}$. The step width in wavelength was set to $2 \mathrm{~nm}$ below $320 \mathrm{~nm}$, and $5 \mathrm{~nm}$ above. The actinic flux calibration of the spectroradiometer was performed before and after the campaign at the Forschungszentrum Jülich in Germany using certified irradiance standards as described in Kraus et al. (2000). No further adjustments for surface albedo were made to the actinic flux spectra.

The MFRSR irradiances were inverted to infer $\varpi_{0, \lambda}$, the asymmetry parameter, $g_{\lambda}$, and aerosol size distribution parameters (effective radius and concentration for the fine mode) using the method of Kassianov et al. (2007). The actinic fluxes from the SR were inverted to find $\varpi_{0, \lambda}$ using a different method, based on the TUV4.4 model. Goering et al. (2005) and Michalsky and Kiedron (2008) describe the use of this model applied to surface irradiance measurements to find $\varpi_{0, \lambda}$ from either UV-MFRSR measurements or Rotating Shadowband Spectrometer measurements. The method we employ here is slightly different than theirs because we use the TUV4.4 with actinic flux, not irradiance, to find $\varpi_{0, \lambda}$. 
Table 1. The five case studies selected for retrievals of MAC.

\begin{tabular}{|c|c|c|c|c|c|c|c|c|c|}
\hline $\begin{array}{l}\text { Date } \\
\text { Julian } \\
\text { Day }\end{array}$ & $\begin{array}{l}\text { Julian } \\
\text { Day }\end{array}$ & $\begin{array}{l}\text { Time } \\
\text { (HH:MM, } \\
\text { LT) }\end{array}$ & $\begin{array}{l}\varpi_{0, \lambda}=300 \mathrm{~nm} \\
\varpi_{0, \lambda}=500 \mathrm{~nm} \\
\varpi_{0, \lambda}=870 \mathrm{~nm}\end{array}$ & $\begin{array}{l}\tau_{\lambda}=300 \mathrm{~nm} \\
\tau_{\lambda}=500 \mathrm{~nm} \\
\tau_{\lambda}=870 \mathrm{~nm}\end{array}$ & $\begin{array}{l}g_{\lambda}=300 \mathrm{~nm} \\
g_{\lambda}=500 \mathrm{~nm} \\
g_{\lambda}=870 \mathrm{~nm}\end{array}$ & $\begin{array}{l}\text { Ångström } \\
\text { exponent } \\
(415 \text { to } \\
870 \mathrm{~nm})\end{array}$ & $\begin{array}{l}\text { Scale } \\
\text { height, } \\
H(\mathrm{~m})\end{array}$ & $\begin{array}{l}\text { Columnar } \\
\mathrm{NO}_{2} \\
\text { (DU) }\end{array}$ & $\begin{array}{l}\text { OA columnar } \\
\text { concentration } \\
\left(\mathrm{g} / \mathrm{m}^{2}\right)\end{array}$ \\
\hline 12 Apr 2003 & 102 & 09:00 & $\begin{array}{l}0.55 \\
0.25 \\
0.099\end{array}$ & $\begin{array}{l}0.68 \\
0.92 \\
0.91\end{array}$ & $\begin{array}{l}0.77 \\
0.72 \\
0.62\end{array}$ & 1.55 & 490 & 2.41 & 0.0147 \\
\hline 14 Apr 2003 & 104 & $09: 35$ & $\begin{array}{l}0.65 \\
0.29 \\
0.11\end{array}$ & $\begin{array}{l}0.78 \\
0.94 \\
0.92\end{array}$ & $\begin{array}{l}0.76 \\
0.70 \\
0.62\end{array}$ & 1.58 & 534 & 1.51 & 0.0090 \\
\hline 15 Apr 2003 & 105 & 09:16 & $\begin{array}{l}0.69 \\
0.32 \\
0.14\end{array}$ & $\begin{array}{l}0.72 \\
0.88 \\
0.81\end{array}$ & $\begin{array}{l}0.77 \\
0.71 \\
0.65\end{array}$ & 1.49 & 706 & 2.60 & 0.0137 \\
\hline 15 Apr 2003 & 105 & $10: 30$ & $\begin{array}{l}0.83 \\
0.37 \\
0.16\end{array}$ & $\begin{array}{l}0.74 \\
0.93 \\
0.87\end{array}$ & $\begin{array}{l}0.76 \\
0.70 \\
0.65\end{array}$ & 1.57 & 706 & 2.60 & 0.0137 \\
\hline 18 Apr 2003 & 108 & $10: 00$ & $\begin{array}{l}0.56 \\
0.28 \\
0.13\end{array}$ & $\begin{array}{l}0.67 \\
0.95 \\
0.90\end{array}$ & $\begin{array}{l}0.76 \\
0.70 \\
0.65\end{array}$ & 1.36 & 1453 & 1.42 & 0.0131 \\
\hline \multicolumn{7}{|c|}{ Median over all cases } & 692 & & \\
\hline
\end{tabular}

To compare the Kassianov et al. (2007) and TUV4.4 methods, we applied the TUV4.4 methodology to the MFRSR irradiance data to infer $\varpi_{0, \lambda}$ and then compared these values to those obtained from the technique of Kassianov et al. (2007). The largest difference was 0.02 , although typical differences are 0.01 or less.

These inversions require knowledge of the spectral surface albedos. These albedos were measured during the MILAGRO campaign using data from the G-1 aircraft flights over Mexico City. The G-1 was equipped with up-looking and down-looking MFRSR heads to find area-averaged surface spectral albedo at the flight level of the G-1. These values were then corrected to surface values using a radiative transfer model. Although these flights took place in March 2006, the albedo values found for this time period should be applicable to early April 2003, the time period of the MCMA2003 campaign on which our analysis is focused.

Our albedo values compare favorably to those found by Coddington et al. (2008) during the MILAGRO campaign. They used upward and downward irradiances from the Solar Spectral Flux Radiometer (SSFR) deployed on an aircraft to find the flight level albedo, which was extrapolated to the surface using a radiative transfer model, similar to the method applied to the G-1 data. For the portion of the flights directly over Mexico City, and for the two days shown in Fig. 4a of Coddington et al. (2008), the values of the surface albedo are, for example, 0.10 and 0.12 at $500 \mathrm{~nm}$. Our value at this wavelength is 0.10 , exhibiting good agreement. At $870 \mathrm{~nm}$, the difference between our albedo and Coddington et al. (2008)'s is 0.015 .
Our albedos were determined only at the five MFRSR wavelengths and, therefore, we do not have direct albedo measurements for $\lambda$ less than $415 \mathrm{~nm}$. However, this is not a problem because, for $\lambda<415 \mathrm{~nm}$, the albedo is very low for almost all surfaces (exception for snow and ice) and minor mischaracterizations of albedo induce negligible error in retrieved $\varpi_{0, \lambda}$. Including all sources of error, the uncertainty of the $\varpi_{0, \lambda}$ values are about \pm 0.03 for all wavelengths (Dubovik et al., 2002; Goering et al., 2005). This estimate does not seem to apply to the $615-\mathrm{nm}$ wavelength channel because the $\varpi_{0, \lambda}$ values often exceeded 1.0. These frequent anomalies, as well as our past experience with this wavelength channel, led us to discard the 615-nm channel in our analysis. The conclusions stated here are not influenced significantly by this exclusion.

Completely clear skies are necessary to derive $\varpi_{0, \lambda}$ and $g_{\lambda}$. Whether the skies are indeed clear can be determined using the algorithm of Long and Ackerman (2000). The need for clear skies severely limited the number of cases that could be studied. During the MCMA-2003 campaign, clear skies generally were observed in the morning hours, and only for a few days. Selected times during these days compose the five case studies examined here; these cases are shown in Table 1, along with the aerosol optical properties $\left(\tau_{\text {ext }}, \lambda, \varpi_{0, \lambda}, g_{\lambda}\right)$ at selected wavelengths, as well as the Ångström exponent determined between the wavelengths of $415 \mathrm{~nm}$ and $870 \mathrm{~nm}$.

The value of $g_{\lambda}$ for wavelengths less than $415 \mathrm{~nm}$ is extrapolated from its value at $415 \mathrm{~nm}$ using the retrieved size distribution and refractive index. We note that the values of $g_{\lambda}$ listed in Table 1 for $300 \mathrm{~nm}$ are all about 0.76 . This value 


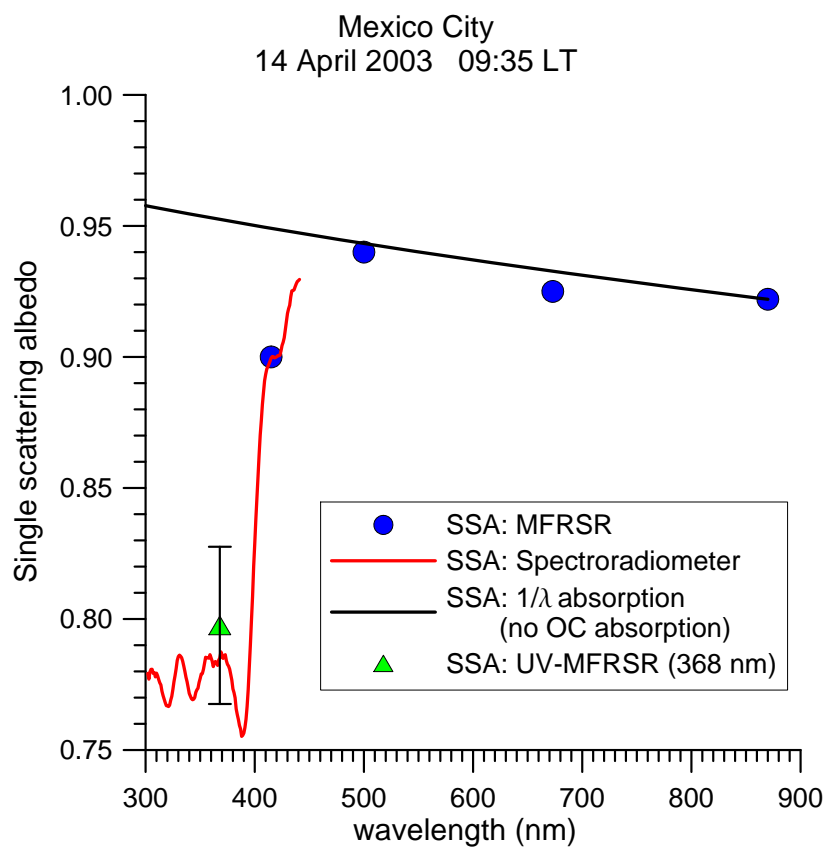

Fig. 1. Single scattering albedo values plotted versus wavelength. These values are derived from the MFRSR, the spectroradiometer, and the UV-MFRSR. Also shown by the black line is the single scattering albedo extrapolated from $870 \mathrm{~nm}$ to lower wavelengths assuming that the absorption follows the $\lambda^{-1}$ rule.

is at the upper end of the range of $g_{\lambda}$ values reported by Wenny et al. (1998) for $312 \mathrm{~nm}$, suggesting the possibility that the extrapolated values are too large. If the values are indeed too large, then the retrieved $\varpi_{0, \lambda}$ values will be too small. For example, sensitivity tests using the TUV4.4 model show that, if we assume that $g_{\lambda}$ equals 0.76 , then the retrieved $\varpi_{0, \lambda}$ value is 0.70 at $300 \mathrm{~nm}$. But if we change $g_{\lambda}$ to $0.66-$ a rather substantial amount - then the retrieved $\varpi_{0, \lambda}$ value rises modestly to 0.725 , still within the uncertainty of $\varpi_{0, \lambda}$ stated above.

Figure 1 illustrates the retrievals of $\varpi_{0, \lambda}$ for one of the five case studies under consideration, 14 April 2003 09:35 LT. This figure shows both $\varpi_{0, \lambda}$ from the SR and the MFRSR. Three features stand out. First, there is the remarkably good agreement between $\varpi_{0, \lambda}$ derived from the SR and the MFRSR at the common wavelength of $415 \mathrm{~nm}$. For the other four cases the disagreement was within the estimated error of 0.03 , and often much better. This good agreement, coming from two different instruments with independent calibrations, bolsters the view that the $\varpi_{0, \lambda}$ values are reasonable. Second, $\varpi_{0, \lambda}$ derived from co-located UV-MFRSR measurements (Goering et al., 2005) is shown for a wavelength of $368 \mathrm{~nm}$, as well as the error bars $( \pm 0.03)$ associated with this retrieval. Agreement to within the retrieval error is evident for the $\varpi_{0, \lambda}$ derived from the SR and UV-MFRSR. Third,

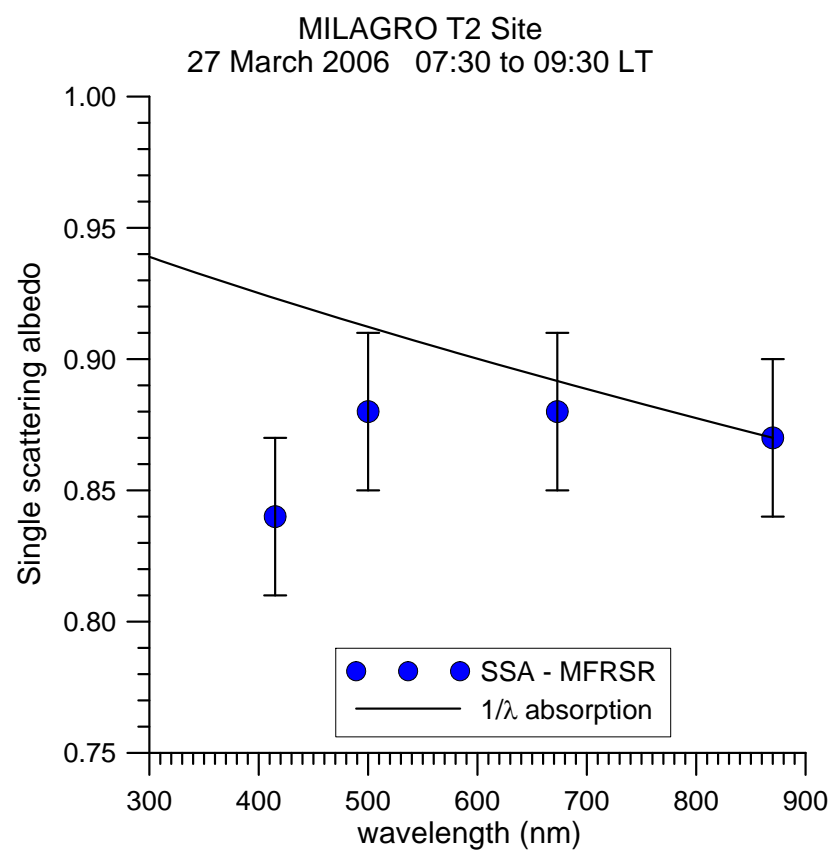

Fig. 2. Single scattering albedo plotted versus wavelength for the T2 MILAGRO site. These values are obtained from MFRSR data. Also shown by the black line is the single scattering albedo extrapolated from $870 \mathrm{~nm}$ to lower wavelengths assuming that the absorption follows the $\lambda^{-1}$ rule. Error bars of \pm 0.03 are shown for the single scattering albedo.

Fig. 1 shows two trends in the variation of $\varpi_{0, \lambda}$ with $\lambda$. Between 870 and $500 \mathrm{~nm}, \varpi_{0, \lambda}$ increases gradually as $\lambda$ decreases. This trend is consistent with absorption that varies as $\lambda^{-1}$, as shown by the black line, which is an extrapolation of the $\varpi_{0, \lambda}$ at $870 \mathrm{~nm}$ to lower wavelengths using the $\lambda^{-1}$ rule as will be discussed in Sect. 3.3. By contrast, for wavelengths less than $500 \mathrm{~nm}$, this trend is reversed, and $\varpi_{0, \lambda}$ now decreases as $\lambda$ continues to decrease. The drop in $\varpi_{0, \lambda}$ is particularly acute for $400 \mathrm{~nm}<\lambda<500 \mathrm{~nm}$, and this drop is typical of all the case studies considered here. Using data from the UV-MFRSR and a CIMEL sunphotometer, Krotkov et al. (2005) have also reported a decrease in $\varpi_{0, \lambda}$ at lower wavelengths for observations made at Greenbelt, Maryland, USA. This decrease is not nearly as sharp as depicted in Fig. 1 as evinced by the difference between the mean $\varpi_{0, \lambda}$ values at $325 \mathrm{~nm}$ and $440 \mathrm{~nm}$; this difference is only 0.04 .

Similar trends in $\varpi_{0, \lambda}$ are also evident during the $2006 \mathrm{MI}-$ LAGRO campaign at several sites, including the rural T2 site (Doran et al., 2007), stationed about $70 \mathrm{~km} \mathrm{NE}$ of Mexico City. Using data from the MFRSR deployed at this site, $\varpi_{0, \lambda}$ was found as shown in Fig. 2 for 27 March 2006. Again, for $\lambda$ less than about $500 \mathrm{~nm}, \varpi_{0, \lambda}$ decreases. This figure also shows by the black line the extrapolation of $\varpi_{0, \lambda}$ at $870 \mathrm{~nm}$ to lower wavelengths, assuming that the absorption follows the $\lambda^{-1}$ rule. For this site, adherence to this rule is less evident 


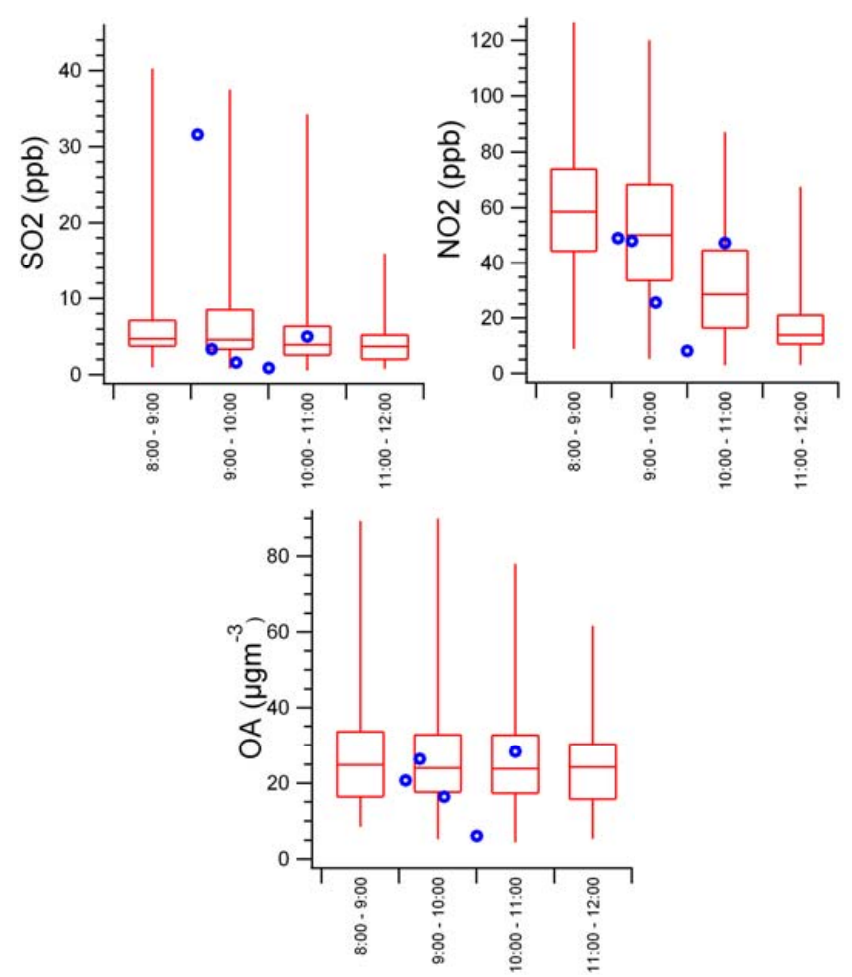

Fig. 3. $\mathrm{SO}_{2}, \mathrm{NO}_{2}$, and organic aerosol concentrations measured during the MCMA-2003 campaign. Whisker plots indicate the diel variability of measurements over the entire campaign. The five case studies discussed here - shown as the blue dots - easily fall within the variability seen throughout the campaign.

than shown in Fig. 1. This lack of adherence cannot be solely attributed to a failure of the $\lambda^{-1}$ rule, because the rule may be followed but is masked by uncertainties in $\varpi_{0, \lambda}$. Recall that this uncertainty is about \pm 0.03 . At $500 \mathrm{~nm}$, the $\lambda^{-1}$ relationship lies just outside the top of the error bar. Of course, had we chosen to extrapolate the $\lambda^{-1}$ relationship from $\varpi_{0, \lambda}$ at $670 \mathrm{~nm}$, the line would lie within all error bars above $500 \mathrm{~nm}$. That $\varpi_{0, \lambda}$ at $415 \mathrm{~nm}$ is lower than $\varpi_{0, \lambda}$ at larger wavelengths is similar to the behavior seen in Mexico City. Without further analysis of the T2 data, beyond the scope of this paper, we cannot be certain that this behavior is caused by the same factors acting at the Mexico City site, such as aerosol composition and size distribution.

2.2 Surface measurements of $\mathrm{SO}_{2}, \mathrm{NO}_{2}$, and $\mathrm{OA}$ concentration

Surface measurements of $\mathrm{SO}_{2}$ and $\mathrm{NO}_{2}$ were obtained from two long-path Differential Optical Absorption Spectroscopy (LP-DOAS) instruments installed on the rooftop of the CENICA building. The light path of DOAS\#1 was directed towards a TELCEL antenna tower in a south-easterly direction at an average height of $16 \mathrm{~m}$ with a $430-\mathrm{m}$ path length (total $860 \mathrm{~m}$ ); that of DOAS\#2 was directed to Cerro de la Estrella in a westerly direction at an average height of $70 \mathrm{~m}$ and a $2210-\mathrm{m}$ path-length (total $4420 \mathrm{~m}$ ). Both DOAS instruments measured $\mathrm{NO}_{2}, \mathrm{SO}_{2}$, among other numerous gases. Concentrations for $\mathrm{SO}_{2}$ and $\mathrm{NO}_{2}$ agreed within error limits (sub ppb level) between both instruments, indicating that the airmass was reasonably well mixed. The measurements are described in more detail in Volkamer et al. (2005).

To convert surface $\mathrm{SO}_{2}$ and $\mathrm{NO}_{2}$ to columnar values in Dobson units (DU), the surface measurements were multiplied by a scale height, $H$. (We discuss the inference of $H$ below.) The inferred $\mathrm{NO}_{2}$ values are listed in Table 1 for the five case studies considered here, and these values fall into a range of 1 to $3 \mathrm{DU}$ that is consonant with other $\mathrm{NO}_{2}$ retrievals in areas of moderate pollution (Cede et al., 2006; Heue et al., 2005; Beirle et al., 2004). Using our columnar values of $\mathrm{NO}_{2}$ and $\mathrm{SO}_{2}$ we corrected the raw $\tau_{\text {ext }, \lambda}$ values obtained from the MFRSR and the SR, and unless otherwise noted, the symbol $\tau_{\text {ext, } \lambda}$ indicates corrected values. For these corrections, the gases were assumed to be well mixed from the surface up to the height $H$, and from this assumption, we determined the columnar abundance of gas. The columnar absorption is calculated as the columnar abundance multiplied by the appropriate absorption coefficient, a function of wavelength. The raw $\tau_{\text {ext, }, \lambda}$ values also were corrected from ozone absorption in the Chappius and Hartley-Higgins bands (Goody and Yung, 1989), assuming a columnar ozone value of $275 \mathrm{DU}$, a climatological value for the atmospheric column in April 2003 obtained from the satellite borne Total Ozone Mapping Spectrometer (TOMS) instrument (http://jwocky.gsfc.nasa.gov). Over all cases considered here, maximum optical thicknesses for these absorbing species are 1.67, 0.03, and 0.04, for ozone ( $303 \mathrm{~nm}), \mathrm{NO}_{2}$ $(400 \mathrm{~nm})$, and $\mathrm{SO}_{2}(300 \mathrm{~nm})$, respectively.

This study relies on actual mass data of the organic component of the aerosol obtained from surface measurements using an AMS deployed at the CENICA site. The instrument and the measurements have been well described in Salcedo et al. (2006), and we refer the reader to this paper for details. For this paper we make no distinction between primary and secondary organic aerosol and combine both these aerosol types under the banner of "organic aerosol".

During the MCMA-2003 campaign, the OA mass of the aerosol varied considerably, ranging from a high of about $90 \mu \mathrm{g} / \mathrm{m}^{3}$ to a low of less than $5 \mu \mathrm{g} / \mathrm{m}^{3}$. Figure 3 shows the concentrations of $\mathrm{SO}_{2}, \mathrm{NO}_{2}$, and organic aerosol during the five case studies as blue dots. These cases are plotted versus time so that, for example, the case study of 18 April 2003 10:00 LT shows up as the blue dot above the time 10:00 LT. The diel variability of these constituents over the course of the campaign also is shown as box-and-whisker plots. The surface concentrations of $\mathrm{NO}_{2}$ show the distinct diel pattern related to the development of the convective boundary layer during the day (Fast et al., 2007); this is less evident for $\mathrm{OA}$ due to the rapid production of secondary organic 
aerosol (SOA) that counteracts vertical dilution (Volkamer et al., 2006, 2007). There is no clear diurnal cycle visible for $\mathrm{SO}_{2}$, for which the variability is strongly dependent on an immediate impact from the Tula power plant (de Foy et al., 2007). For the case study of 18 April 2003, all three concentrations exhibit a marked decrease from the four other cases. This day was a national holiday and emissions from surface sources, notably traffic, were much less than normal.

\subsection{Finding the scale height, $H$}

The scale height, $H$, is the critical parameter for converting surface measurements of $\mathrm{SO}_{2}, \mathrm{NO}_{2}$, and $\mathrm{OA}$ concentration to columnar measurements. The scale height can be described as the depth of the atmospheric mixed layer below which we expect to find the bulk of the pollution, i.e., gases and aerosols. In the MCMA, $H$ varies as a function of the time of day being relatively low and constant $(\sim 600 \mathrm{~m})$ during the late night and early morning hours, but increasing substantially after about 10:30 LT because of the development of the convective boundary layer and efficient vertical mixing of surface pollutants (de Foy et al., 2006). The case studies listed in Table 1 occur in the morning hours, prior to the start of the convective mixing, making the inference of $H$ easier because it is not rapidly changing during the times of interest.

To find $H$, we follow a simple diagnostic approach using surface measurements of BC and MFRSR data taken at 673 and $870 \mathrm{~nm}$, where OA absorption should be very small relative to the absorption by BC. Specifically, we equate the absorption inferred from the MFRSR, $\tau_{\mathrm{abs}, \lambda}$, to the absorption calculated from the product of the $\mathrm{BC}$ columnar mass, the $\mathrm{BC}$ specific absorption, and the scale height. This equality is expressed as

$\left(1-\varpi_{0, \lambda}\right) \tau_{\mathrm{ext}, \lambda}=\tau_{\mathrm{abs}, \lambda}=\rho_{\mathrm{BC}} H \alpha_{\mathrm{BC}, \lambda}$,

where $\rho_{\mathrm{BC}}$ is the surface concentration of $\mathrm{BC}, \rho_{\mathrm{BC}} H$ is the columnar mass, and $\alpha_{\mathrm{BC}, \lambda}$ is the specific absorption of $\mathrm{BC}$ (where we have explicitly noted that $\alpha_{\mathrm{BC}}$ is a function of $\lambda$ ). After assuming a plausible value for $\alpha_{\mathrm{BC}, \lambda}$, this equation provides a means of diagnosing $H$, because all other variables are either inferred from MFRSR measurements $\left(\varpi_{0, \lambda}\right.$ and $\left.\tau_{\text {ext }, \lambda}\right)$ or measured directly $\left(\rho_{\mathrm{BC}}\right)$.

For the MCMA field campaign, surface BC measurements were made with an aethalometer (Model No. RTAA-1000, Magee Scientific, Berkeley, California, USA; Hansen et al., 1984; http://www.mageesci.com/), operated at a flow rate of 41/min using ambient (i.e. undried) air. Determining an appropriate value of $\alpha_{\mathrm{BC}, \lambda}$ requires knowledge of the mixing state of BC; that is, is it externally or internally mixed? Electron Micrographs (SEM) of BC-containing particles shown in Johnson et al. (2005) show that the BC is mostly internally mixed. For these internal mixtures, $\alpha_{\mathrm{BC}, \lambda}$ should lie between the value for externally mixed $\mathrm{BC}$, and the maximum value for internally mixed BC. For the case of uncoated BC, Bond and Bergstrom (2006) suggest the value of $7.5 \pm 1.2 \mathrm{~m}^{2} / \mathrm{g}$, at
$550 \mathrm{~nm}$. On the other hand, Fuller et al. (1999) state that the maximum value of $\alpha_{\mathrm{BC}, \lambda}$ for coated $\mathrm{BC}$ is unlikely to exceed $10 \mathrm{~m}^{2} / \mathrm{g}$ (see also Bond et al., 2006). Measurements in the MCMA seem to confirm this picture. For example, using a photoacoustic absorption spectrometer and an OC/EC instrument Doran et al. (2007) determined $\alpha_{\mathrm{BC}, \lambda}$ at the T1 MILAGRO site to be $8.9 \mathrm{~m}^{2} / \mathrm{g}$ at $550 \mathrm{~nm}$. At this site, the BC is expected to be at least partially coated, depending on the time of day (Doran et al., 2008). Barnard et al. (2007) estimated $\alpha_{\mathrm{BC}, \lambda}$ to be $8.2 \mathrm{~m}^{2} / \mathrm{g}$ at $550 \mathrm{~nm}$ over MC. We chose this value because it was inferred using the same MFRSR data as this study.

Individual inferences of the $H$ at the time resolution of the MFRSR measurements ( $20 \mathrm{~s}$ ) can be noisy, and to reduce this noise, we take the median of $\mathrm{H}$ values over a time interval starting at about 08:00 LT and extending to about 10:00 LT. As mentioned above, $H$ is not expected to change much between these times. We first note that, for a given day, $H$ derived from the 673-nm MFRSR channel is usually within $10 \%$ of that derived from the $870-\mathrm{nm}$ channel, with no systematic difference between the two wavelengths; that is, $H$ is not always larger at one wavelength. Table 1 lists the median heights for each day of interest, where the median is obtained from the combined set of 673-nm and 870-nm inferences. The scale heights are all about the same except for the last day, which has a much larger scale height than the other days. We have been unable to determine why this is so. The grand median over all days is $692 \mathrm{~m}$.

We acknowledge that this method is subject to considerable uncertainties, not the least of which is the aethalometer measurements. These measurements are based on light attenuation, rather than a direct chemical determination of BC mass concentration, and are subject to large uncertainties (for example, see Jeong et al., 2004; Kirchstetter and Novakov, 2007, among others) that could considerably compromise the determination of $H$. Some of this large uncertainty may stem from filter contamination by OA, as discussed in Cappa et al. (2008), Lack et al. (2008), and Subramanian et al. (2007). This contamination may artificially enhance absorption that is attributed to BC, which in turn would result in BC concentrations that are too large, and therefore tend to make our inferences of $H$ too small. Fortunately, we have an independent, but not perfect way, to corroborate these heights by comparing them to aerosol mixing heights derived from lidar measurements during the later part of the MCMA campaign. We would have preferred to use the lidar measurements directly to find $H$, but the lidar was not operational on the dates of our case studies.

Specifically, the lidar depolarization measurements were made from 20 April 2003, extending through the end of the month from which aerosol mixing heights were found. When these mixing heights are plotted versus time of day, a distinct pattern is seen that does not vary significantly from day-today (Barnard et al., 2005) suggesting that the mixing heights derived for the end of April are applicable to the middle of 
the month as well. Between the hours of 08:00 LT and 10:00 LT, the median of the lidar mixing height was $566 \mathrm{~m}$, which is about 20\% less than the median of $H$ quoted above, $692 \mathrm{~m}$. (If 18 April 2003 is not considered, the median becomes $623 \mathrm{~m}$, and is within $10 \%$ of the lidar median mixing height.) Given the difficulties in determining $H$, this level of agreement seems satisfactory, but it must also be recognized that the uncertainties in $H$, around $20 \%$, is a floor to the overall uncertainty of the MAC values derived here.

\subsection{Calculating the MAC}

Once $H$ is determined, it is easy to find the MAC using Eq. (1). The denominator is known from our estimate of $H$ and the surface OA concentration. The total absorption optical thickness is known from analysis of data obtained from the MFRSR and the SR. It remains to find the contribution to absorption from $\mathrm{NO}_{2}, \mathrm{SO}_{2}, \mathrm{BC}$, ozone, and dust that compose the $\tau_{\mathrm{abs}, \lambda, \text { other }}$, and then remove this quantity from the total absorption to isolate the absorption due to OA. This procedure assumes that the primary absorbers in the near-UV spectral region are $\mathrm{OA}, \mathrm{BC}$, dust, $\mathrm{SO}_{2}, \mathrm{NO}_{2}$, and ozone. $\mathrm{Ab}-$ sorption by $\mathrm{NO}_{2}, \mathrm{SO}_{2}$, and ozone is taken into account for the inferences of $\tau_{\mathrm{ext}, \lambda}$ and $\varpi_{0, \lambda}$ and needs no further discussion.

To estimate the MAC, the following formula is used,

$$
\operatorname{MAC}(\lambda)=\left(\left(1-\varpi_{0, \lambda}\right) \tau_{\mathrm{ext}, \lambda}-C_{\mathrm{BC}}\left(\lambda_{0} / \lambda\right)-D(\lambda)\right) / \rho_{\mathrm{OA}} H,
$$

where $C_{\mathrm{BC}}$ is a constant and the expression $C_{\mathrm{BC}}\left(\lambda_{0} / \lambda\right)$ accounts for the absorption by $\mathrm{BC}$, and $D(\lambda)$ accounts for dust absorption, which for the cases we are studying is negligible, as discussed below. Discussing each term in Eq. (3) in turn, we again state that $\left(1-\varpi_{0, \lambda}\right) \tau_{\mathrm{ext}, \lambda}$ is the total aerosol absorption in the atmospheric column (recall that gaseous absorption already has been taken into account). This quantity is calculated trivially for the MFRSR wavelengths. However, for $\lambda<415 \mathrm{~nm}$, where no MFRSR data exist, we need to know $\tau_{\text {ext, } \lambda}$ to find the absorption. For this task, we use the well-known Ångström relationship to extrapolate the $\tau_{\text {ext }, \lambda=500 \mathrm{~nm}}$ to lower wavelengths. This relationship can be expressed in the usual manner as

$$
\tau_{\mathrm{ext}, \lambda}=\tau_{\mathrm{ext}, \lambda_{0}=500 \mathrm{~nm}}\left(\frac{\lambda}{\lambda_{0}=500 \mathrm{~nm}}\right)^{-n},
$$

where $n$ is the Ångström exponent, determined from the 415$\mathrm{nm}$ and 870-nm channels of the MFRSR and shown in Table 1. Plots of $\tau_{\mathrm{ext}, \lambda}$ determined from Eq. (4) overlaid by MFRSR-derived $\tau_{\text {ext }, \lambda}$ values, as well as an additional value from the UV-MFRSR at $368 \mathrm{~nm}$ (Goering et al., 2005), indicate that the Ångström relationship is satisfied well between the wavelengths of $368 \mathrm{~nm}$ and $870 \mathrm{~nm}$. This in turn suggests that the extrapolation of the extinction to $300 \mathrm{~nm}$ will be reasonably good, although optical thickness measurements at $300 \mathrm{~nm}$ would be necessary to confirm this assertion.
For the next term, $C_{\mathrm{BC}}$, we specify it as $\tau_{\mathrm{abs}, \lambda}=\left(1-\varpi_{0, \lambda}\right) \tau_{\mathrm{ext}, \lambda}$ for $\lambda$ equal to $870 \mathrm{~nm}-\mathrm{a}$ wavelength at which we assume that there is no absorption by dust or AO. The extrapolation of absorption to lower wavelengths is performed using the well-known $1 / \lambda$ rule (Bond and Bergstrom, 2006), which appears to be a good assumption between 500 and $870 \mathrm{~nm}$ (e.g. the $\lambda^{-1}$ curve in Fig. 1). While strictly speaking, the $1 / \lambda$ rule is valid only in the small particle limit (Bohren and Huffman, 1983), several studies (Kirchstetter et al., 2004; Bergstrom et al., 2002, and references therein) have shown that it holds approximately for realistically sized aerosols in locations where BC absorption is thought to be dominant. For example, Fig. 1 in Kirchstetter et al. (2004) shows a very good fit of the "normalized light attenuation" to a $\lambda^{-1}$ relationship in a wavelength range of $330 \mathrm{~nm}$ to $1000 \mathrm{~nm}$ (the range in which the attenuation measurements were made).

Finally, the pattern of decreasing $\varpi_{0, \lambda}$ with decreasing $\lambda$ in the near-UV can sometimes be a signature of aerosol loadings with a large dust component (Bergstrom et al., 2007; Dubovek et al., 2002; Sokolik and Toon, 1999). The dust term, $D(\lambda)$, is assumed to be non-zero only in the wavelength region $300 \mathrm{~nm}<\lambda<500 \mathrm{~nm}$ because, like OA, dust is thought to absorb mostly in the UV and near-UV spectral region (Sokolik and Toon, 1999). For highly absorbing components of soil, such as iron oxides (hematite, goethite, etc.), the MAC has been studied in the near-UV and visible spectral regions, providing MAC values from which we can determine $D(\lambda)$. Alfaro et al. (2004) found that the MACs of dust samples, from three different areas but all containing some iron oxide, are about $1 \mathrm{~m}^{2} / \mathrm{g}$ at $325 \mathrm{~nm}$, dropping to about $0.1 \mathrm{~m}^{2} / \mathrm{g}$ at $660 \mathrm{~nm}$. Using an aerosol chamber Linke et al. (2006) measured MACs of dust samples from Cairo and Morocco. The MAC was found to be about $1 \mathrm{~m}^{2} / \mathrm{g}$ at $266 \mathrm{~nm}$, and almost zero at $532 \mathrm{~nm}$. These values fit the conventional picture of dust absorption: large at low wavelengths $(350-300 \mathrm{~nm})$ and then falling to almost zero at visible wavelengths.

We now argue that $D(\lambda)$ is so small that it may be neglected. Assuming that the entire dust burden over MC is some oxide of iron that absorbs solar radiation, and using the studies above as a guide, we take the MAC for dust as $1 \mathrm{~m}^{2} / \mathrm{g}$ at $300 \mathrm{~nm}$. Multiplying this by the columnar mass of the soil component, $M_{\text {soil }}=H \rho_{\text {soil }}$, yields the absorption, where $\rho_{\text {soil }}$ is the surface concentration. As shown in Salcedo et al. (2006), the soil content of the aerosol is about $7 \%$ of the $\mathrm{PM}_{2.5}$ mass, with an average $\rho_{\text {soil }}$ value of $2.1 \mu \mathrm{g} / \mathrm{m}^{3}$, yielding a dust absorption of about 0.0015 at $300 \mathrm{~nm}$. A typical value of the total absorption at $300 \mathrm{~nm}$ is $0.2\left(=\left(1-\varpi_{0, \lambda}=300 \mathrm{~nm}\right) \tau_{\mathrm{ext}, \lambda=300 \mathrm{~nm}}\right)$ and clearly the dust absorption is negligible. 

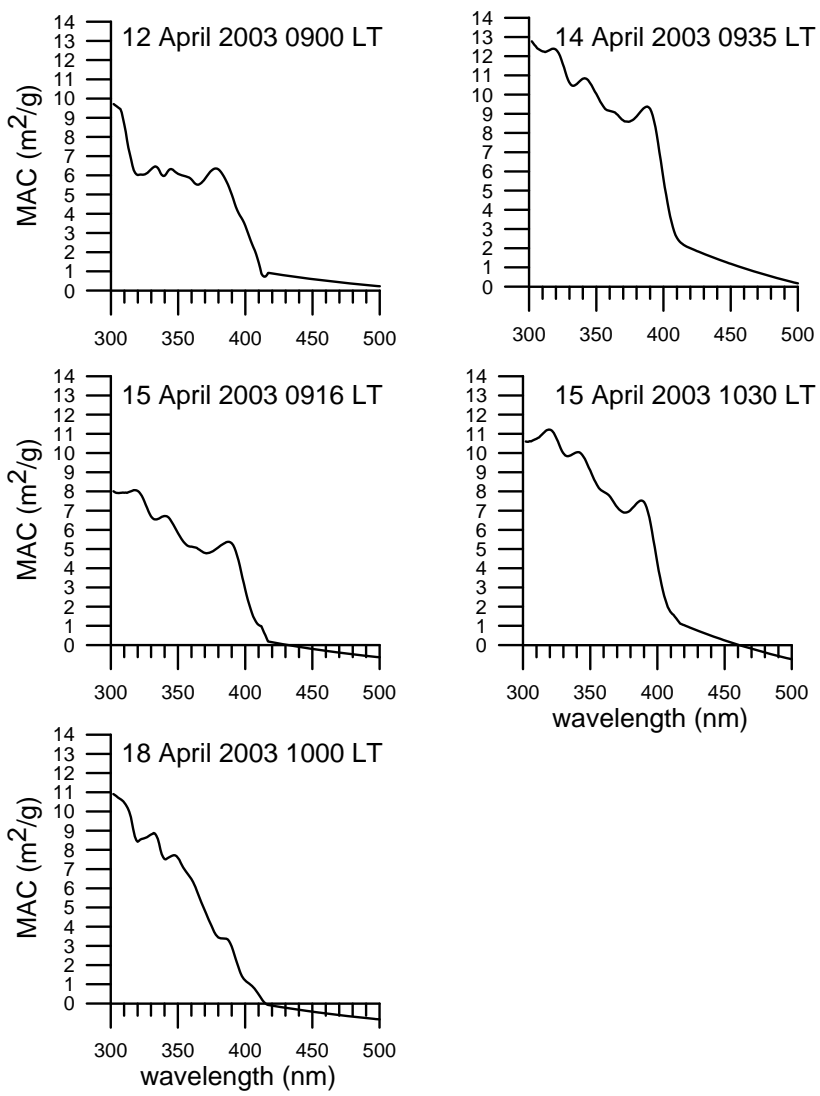

Fig. 4. MAC for organic carbon, for the five cases listed in Table 1.

We did not have comparable measurements at the MILAGRO T2 site from which we could estimate dust absorption. However, for the specific MILAGRO case shown in Fig. 2, rainfall occurred prior to this day that would tend to scavenge dust from the atmosphere. Additionally, airborne lidar polarimeter data indicated that, after the rainfall, significant amounts of dust were indeed removed from the atmosphere (J. Hair, personal communication). Therefore it is unlikely that the $\varpi_{0, \lambda}$ behavior seen at T2 on this day can be attributed to dust.

Neglecting dust absorption and making substitutions discussed above, Eq. (3) becomes

$\operatorname{MAC}(\lambda)=\left(\begin{array}{l}\left(1-\varpi_{0, \lambda}\right) \tau_{\mathrm{ext}, \lambda_{0}=500 \mathrm{~nm}}\left(\frac{\lambda}{\lambda_{0}(=500 \mathrm{~nm})}\right)^{-n} \\ -\left(\left(1-\varpi_{0, \lambda=870 \mathrm{~nm}}\right) \tau_{\mathrm{ext}, \lambda=870 \mathrm{~nm}}\right)\left(\frac{\lambda_{0}(=870 \mathrm{~nm})}{\lambda}\right)\end{array}\right) / \rho_{\mathrm{OA}} H$.

Eq. (5) is applied at wavelengths used in this study. The notation $\lambda_{0}(=500 \mathrm{~nm})$ means that $\lambda_{0}$ is set equal to $500 \mathrm{~nm}$.

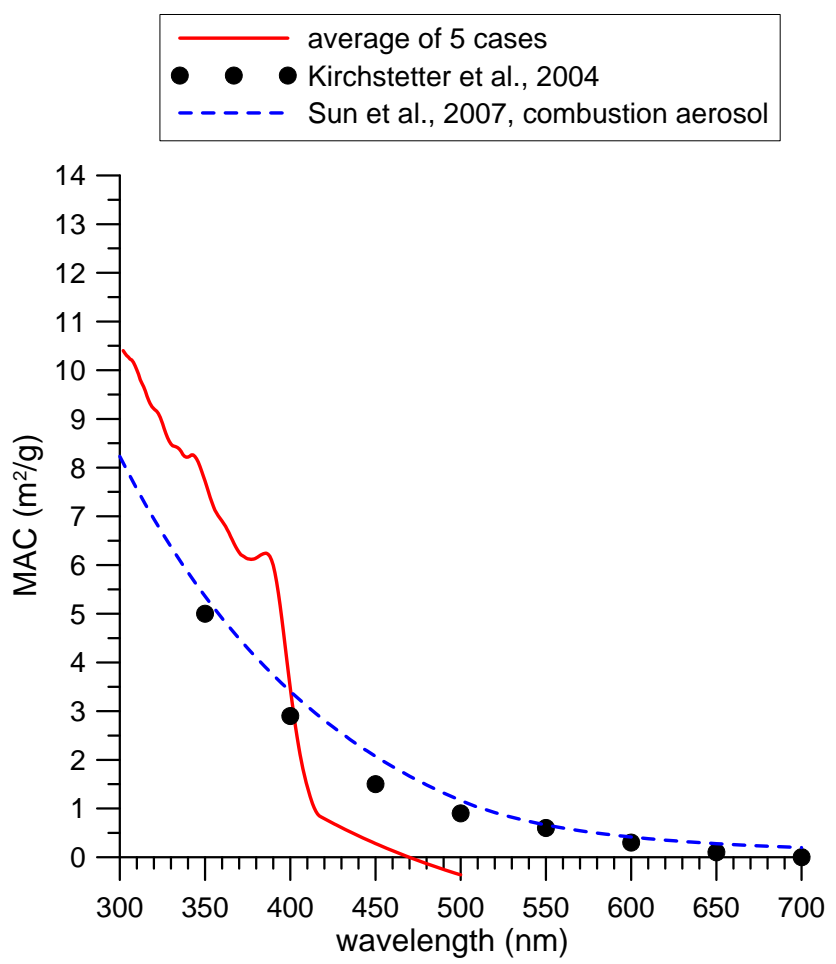

Fig. 5. MAC for the average of the five cases listed in Table 1. For the sake of comparison, the MAC inferences from Kirchstetter et al. (2004) and Sun et al. (2007) are also shown.

\section{Results}

\subsection{MAC}

For the five cases listed in Table 1 we calculate the MAC for wavelengths extending from $300 \mathrm{~nm}$ up through $500 \mathrm{~nm}$. For these calculations, we used the columnar concentration of OA listed in the last column of this table; recall that the columnar concentration is the surface concentration $\rho_{\mathrm{OA}}$ multiplied by the scale height, $H$. To avoid using a single point measurement of $\rho_{\mathrm{OA}}$, subject to random fluctuations and possibly not representative of the actual concentration, we use a time average of $\rho_{\mathrm{OA}}$ for the period 08:00 LT to 10:00 LT. The other variables that compose Eq. (5) fluctuate much less over time and, for them, we use five minute averages.

Figure 4 shows MAC for each of the five cases. These cases all exhibit about the same behavior: the MAC is large, about $10 \mathrm{~m}^{2} / \mathrm{g}$ around $300 \mathrm{~nm}$, and drops to about zero at $500 \mathrm{~nm}$. For some cases the MAC values near $500 \mathrm{~nm}$ are less than zero; this behavior is indicative of the large uncertainties in finding MAC, discussed below. For example, if the inferred $\mathrm{NO}_{2}$ concentrations listed in Table 1 are reduced by $1 \mathrm{DU}$, then all the MAC values at $500 \mathrm{~nm}$ are 
Table 2. Absorption Ångström Exponents (AAE) over two wavelength ranges.

\begin{tabular}{lllll}
\hline $\begin{array}{l}\text { Date } \\
\text { Julian Day }\end{array}$ & $\begin{array}{l}\text { Julian } \\
\text { Day }\end{array}$ & $\begin{array}{l}\text { Time } \\
\text { (HH:MM, } \\
\text { LT) }\end{array}$ & $\begin{array}{l}\text { AAE: } \\
\text { 300-500 } \\
\mathrm{nm}\end{array}$ & $\begin{array}{l}\text { AAE: } \\
\text { 300-870 } \\
\mathrm{nm}\end{array}$ \\
\hline 12 Apr 2003 & 102 & $09: 00$ & 4.5 & 2.8 \\
14 Apr 2003 & 104 & $09: 35$ & 4.1 & 2.6 \\
15 Apr 2003 & 105 & $09: 16$ & 3.2 & 1.9 \\
15 Apr 2003 & 105 & $10: 30$ & 4.2 & 2.2 \\
18 Apr 2003 & 108 & $10: 00$ & 5.1 & 2.4 \\
\hline
\end{tabular}

positive. An additional feature of these retrievals is the significant drop in MAC seen around $400 \mathrm{~nm}$ near the spectral region of maximum $\mathrm{NO}_{2}$ absorption. However, this feature is unlikely to be an artifact of not properly accounting for $\mathrm{NO}_{2}$ absorption. We attempted to eliminate this feature by varying the inferred $\mathrm{NO}_{2}$ concentration to see if the sharpness of this feature could be reduced and it could not. Thus, we attribute this striking change at $400 \mathrm{~nm}$ to some compound in the aerosol, or perhaps an unknown absorbing trace gas.

Figure 5 shows the average of all five cases, along with other MAC determinations from some of the studies mentioned in Sect. 1. Specifically, Fig. 5 contains: (1) the MACs from Kirchstetter et al. (2004) that were obtained from a laboratory analysis of aerosol specimens collected in the field in locations in the US, and (2) an analysis of existing laboratory studies of organic absorption to find plausible MACs for atmospheric aerosols (Sun et al., 2007). We display the "combustion" results from Sun et al. (2007). Given the wide variation in the three methodologies shown in Fig. 5, the agreement is reasonably good.

For the sake of comparison, Table 2 lists AAEs derived from our data, for wavelength ranges between 300 to $500 \mathrm{~nm}$, and 300 to $870 \mathrm{~nm}$. Averaged over all cases, the AAE between 300 to $870 \mathrm{~nm}$ is about 2.4, and is consistent with other values reported in the literature for aerosols that might be expected to have a significant amount of organic carbon (e.g. biomass, some laboratory generated soot; Schnaiter et al., 2006); these values are summarized in Table 2 in Bergstrom et al. (2007).

\subsection{Random and systematic uncertainties}

The MACs shown in Fig. 4 are subject to significant uncertainty discussed here. The overall uncertainty stems from the individual errors of each component that composes Eq. (5). These components, as well as their estimated errors, are listed in Table 3. These errors are straightforward to interpret, with the following caveats. Regarding the Ångström exponent, $n$, we tacitly assume that the Angström relationship, Eq. (4), is valid for the extrapolation of $\tau_{\text {ext }, \lambda}$ to wavelengths less than $415 \mathrm{~nm}$. Accordingly, we assume that errors associated with the use of this equation stem from uncertainties in determining $n$ from $\tau_{\text {ext, } \lambda}$ values at two wavelengths (415 and $870 \mathrm{~nm}$ ). This issue has been discussed thoroughly in Wagner and Silva (2008), who note that the error in finding $n$ is less under turbid conditions, a criterion that is certainly met in the MCMA. This "turbid conditions" error is quoted in Table 3. We also assume that the $1 / \lambda$ extrapolation of BC absorption at $870 \mathrm{~nm}$ to lower wavelengths is error free. It is difficult to determine the error associated with $H$ because the only independent verification comes from the lidar measurements. As mentioned above, a difference of about $20 \%$ is found between the median of the lidar-derived heights and the $\mathrm{H}$ values from our method. Without additional information, we assume that the error is about $20 \%$.

The errors listed in Table 3 are used to find the overall uncertainty for the MAC values, assuming that these errors are random and uncorrelated. We calculate the uncertainty by assuming that each variable in Eq. (5) is normally distributed with means as listed in Table 1, and standard deviations as listed in Table 3. Then, using Monte Carlo simulations the distribution of MAC values and the corresponding standard deviation is derived. The standard deviation values are typically about $3.5 \mathrm{~m}^{2} / \mathrm{g}$ at $300 \mathrm{~nm}$ and $1.7 \mathrm{~m}^{2} / \mathrm{g}$ at $500 \mathrm{~nm}$ for an individual case. Statistical averaging over individual cases will, of course, reduce the random error.

These uncertainty estimates do not include the effect of systematic errors, which are virtually unknowable, and possibly a much more potent source of error. To illustrate the possible effect of the systematic component, we note that reducing the $\mathrm{NO}_{2}$ concentration by $1 \mathrm{DU}$ increases the MAC at wavelengths shorter than $450 \mathrm{~nm}$. The most dramatic increase occurs at wavelengths near the peak in $\mathrm{NO}_{2}$ absorption around $410 \mathrm{~nm}$. For example, at $415 \mathrm{~nm}$ the MAC values increase by about $1.3 \mathrm{~m}^{2} / \mathrm{g}$ when the $\mathrm{NO}_{2}$ concentration is reduced by 1 DU. At $500 \mathrm{~nm}$, the increase is about $0.5 \mathrm{~m}^{2} / \mathrm{g}$. To attempt to account for all the systematic errors, we calculate a "worst case" uncertainty that assumes all errors listed in Table 3 act to maximize the overall uncertainty; that is, for each variable (i.e. $\tau_{\mathrm{ext}, \lambda}$ ) we assume that the error is maximum, and we allow no opportunity for an error in the positive direction to cancel an error in the other direction. For this circumstance, the errors at 300 and $500 \mathrm{~nm}$ are about $\pm 8 \mathrm{~m}^{2} / \mathrm{g}$ and $\pm 2 \mathrm{~m}^{2} / \mathrm{g}$, respectively. We must emphasize, however, that these uncertainty estimates assume that "everything possible that can go wrong does go wrong" and therefore they are unlikely to be representative of the true systematic uncertainty, but rather serve as conservative estimates of upper bounds of the systematic error. The magnitude of the random and systematic error at $500 \mathrm{~nm}$ may account for the negative MAC values as observed for some of the case studies shown in Fig. 4. 
Table 3. Summary of individual errors.

\begin{tabular}{|c|c|c|c|}
\hline Quantity & Error & Comments & Source \\
\hline$\varpi_{0, \lambda}$ & \pm 0.03 & & $\begin{array}{l}\text { Dubovik et al. (2002), Goering et al. (2005), } \\
\text { Kassianov et al. (2007) }\end{array}$ \\
\hline$\tau_{\text {ext }, \lambda}$ & \pm 0.01 & valid for 500 and $870 \mathrm{~nm}$ & Alexandrov et al. (2007), Michalsky et al. (2001) \\
\hline Ångström exponent, $n$ & \pm 0.17 & Turbid conditions, $n=1.5$ & Wagner and Silva (2008) \\
\hline$H$ & $\pm 20 \%$ & $\begin{array}{l}\text { educated guess, comparison } \\
\text { to lidar mixing heights }\end{array}$ & \\
\hline$\rho_{\mathrm{OA}}$ & $\pm 10 \%$ & guess & \\
\hline $\mathrm{NO}_{2}$ & $\pm 1 \mathrm{DU}$ & guess & \\
\hline
\end{tabular}

Table 4. Results of radiative transfer calculation of TOA and surface net fluxes, for the three cases indicated. The net fluxes are defined positive in the downward direction, and are "instantaneous" fluxes for the time of this case study (14 April 2003 09:35 LT).

\begin{tabular}{llll}
\hline Case & $\begin{array}{l}\text { TOA } \\
\text { net flux } \\
\left(\mathrm{W} / \mathrm{m}^{2}\right)\end{array}$ & $\begin{array}{l}\text { Surface } \\
\text { net flux } \\
\left(\mathrm{W} / \mathrm{m}^{2}\right)\end{array}$ & $\begin{array}{l}\text { Difference } \\
\left(\mathrm{W} / \mathrm{m}^{2}\right)\end{array}$ \\
\hline No aerosol & 816 & 667 & 149 \\
Observed aerosol & 805 & 629 & 176 \\
BC only & 803 & 635 & 168 \\
\hline
\end{tabular}

\subsection{Implications for solar heating rates}

The absorption by OA, if not accounted for in radiative transfer models, could have a significant effect on calculated photolysis rates and aerosol forcing. Here we focus on aerosol forcing by examining the energy deposited in the atmosphere, with and without the absorption depicted in Fig. 5, in a manner similar to Hoffer et al. (2006). We use data from case 14 April 2004 09:35 LT ( $\left.\mu_{0} \approx 0.7\right)$ listed in Table 1 and make one calculation, termed "observed aerosol", of the broadband solar fluxes assuming the inferred $\varpi_{0, \lambda}$ depicted in Fig. 1. The calculations are made using the SBDART radiative transfer model (Ricchiazzi et al., 1998). Then another calculation is made assuming that the MAC of OA is $0 \mathrm{~m}^{2} / \mathrm{g}$ at all wavelengths, while keeping the asymmetry parameter and $\tau_{\text {ext }}$ unchanged. This assumption implies that the only absorber is $\mathrm{BC}$ and requires changes to the $\varpi_{0, \lambda}$ for wavelengths less than $870 \mathrm{~nm}$. The new $\varpi_{0, \lambda}$ are found by extrapolating the $\mathrm{BC}$ absorption from $870 \mathrm{~nm}$ to lower wavelengths using the $\lambda^{-1}$ rule while keeping the extinction fixed, such that

$\varpi_{0, \lambda}=1-\frac{\left(1-\varpi_{0, \lambda=870 \mathrm{~nm}}\right) \tau_{\mathrm{ext}, \lambda=870 \mathrm{~nm}}}{\tau_{\mathrm{ext}, \lambda}} \frac{870}{\lambda} ;$

this formula is essentially the same as Eq. (2) found in Berg- strom et al. (2002). The $\varpi_{0, \lambda}$ for the two cases are shown in Fig. 1. We call this calculation "BC only". Finally, a calculation is made assuming no aerosol at all $\left(\tau_{\text {ext }, \lambda}=0\right)$, and labeled "No aerosol".

The results of these three calculations are shown in Table 4 that lists the instantaneous top of atmosphere (TOA) and surface net fluxes as well as the difference. The net fluxes are defined positive downward. For the case "No aerosol", the difference in TOA and surface fluxes is the energy deposited in the atmosphere $\left(\mathrm{W} / \mathrm{m}^{2}\right)$ due to absorption by water vapor and other gases. When aerosols are added, we note that, as expected, the net effect is to cool the earth/atmosphere, because the incoming energy, the net TOA flux, is decreased in the two cases with aerosols when compared to the "No aerosol" case. However, when aerosols are allowed to exist in the calculation, additional atmospheric absorption does occur. For the case with BC only, the additional heating due to aerosols is $19 \mathrm{~W} / \mathrm{m}^{2}\left(=168 \mathrm{~W} / \mathrm{m}^{2}\right.$; $\mathrm{BC}$ only $-149 \mathrm{~W} / \mathrm{m}^{2}$; no aerosol). On the other hand, for the observed case, the additional heating is $27 \mathrm{~W} / \mathrm{m}^{2}$. Thus, excluding the effect of OA absorption below $500 \mathrm{~nm}$ results in a large error in computing aerosol absorption, at least for this case. If there is significant $\mathrm{OA}$ absorption in the visible as indicated by the findings of Sun et al. (2007) and Kirchstetter et al. (2004) and illustrated in Fig. 5, then this error would be significantly larger.

\section{Conclusions}

We have calculated the mass absorption coefficient (MAC, with units $\mathrm{m}^{2} / \mathrm{g}$ ) for the organic part of the aerosol in the shortwave spectral region. For these calculations, we used measurements taken during the MCMA-2003 field campaign, supplemented by some data from the 2006 MILAGRO campaign. Both field efforts took place in and around Mexico City. Two important features of this inference of the MAC are: (1) the measurements upon which it is based are entirely in situ, and do not require laboratory analysis, and 
(2) the MAC so calculated is "radiatively correct", meaning that the MAC is consistent with the observed surface shortwave radiation field. The disadvantage of this method is that the uncertainty is rather large.

The MAC is highest at $300 \mathrm{~nm}$, with a value of about $10.5 \mathrm{~m}^{2} / \mathrm{g}$, and gradually decreases to about $0 \mathrm{~m}^{2} / \mathrm{g}$ at about $500 \mathrm{~nm}$ (see Fig. 5), and a comparison of these MAC values with those found by Kirchstetter et al. (2004) - a laboratory analysis of aerosol sample collected in the field, and Sun et al. (2007) - an analysis of laboratory studies of the absorption by organic compounds, shows reasonably good agreement. For individual cases, the uncertainties are typically about $3.5 \mathrm{~m}^{2} / \mathrm{g}$ at $300 \mathrm{~nm}$ and $1.7 \mathrm{~m}^{2} / \mathrm{g}$ at $500 \mathrm{~nm}$. These uncertainties are due to random errors in the measurements and do not include the effect of systematic error, which is much more difficult to determine. We estimate an upper bound to the systematic error by assuming that the individual sources of error listed in Table 3 work in concert to maximize the overall uncertainty. This "worst case estimate" of the systematic uncertainty is about $8 \mathrm{~m}^{2} / \mathrm{g}$ at $300 \mathrm{~nm}$ and $2 \mathrm{~m}^{2} / \mathrm{g}$ at $500 \mathrm{~nm}$. Such large uncertainties are very unlikely to be realized, however, because they are calculated assuming that no error cancellation occurs and each individual error source is acting with maximum force.

Neglecting the absorption by OA in radiation transfer calculations certainly would affect calculated photolysis rates that are influenced primarily by radiation in the near-UV region. For example, Castro et al. $(1997,2001)$ note that uncertainties in $\varpi_{0, \lambda}$ (or equivalently, refractive index) in the near-UV can significantly influence calculated $\mathrm{NO}_{2}$ photolysis rates. Like $\mathrm{NO}_{2}$ photolysis, most photochemical reactions are driven by photons with wavelengths less than $400 \mathrm{~nm}$ (e.g. Fig. 2 in Kraus and Hofzumahaus, 1998) making an even stronger case to include OA absorption in photochemical calculations. For Mexico City in particular, approximately $85 \%$ of the radical production depends on the amount of sunlight that reaches the ground (Volkamer et al., 2007), and the formation of secondary pollutants is radical limited (Lei et al., 2007; Volkamer et al., 2007). Effectively this means that significant organic aerosol absorption acts to slow down the rate of formation of secondary pollutants like ozone and SOA.

Furthermore, organic aerosol absorption needs to be accounted for in radiative transfer calculations that underlie quantitative satellite retrievals, particularly for those trace gases that absorb light at wavelengths shorter than $420 \mathrm{~nm}$; i.e., $\mathrm{HCHO}, \mathrm{SO}_{2}$, possibly $\mathrm{NO}_{2}$, and other gases. In the polluted atmosphere the apparent vertical column density could be underestimated by at least $20 \%$ in optically thin media, if typical values of 0.95 are used for $\varpi_{0, \lambda}$. In air masses of high aerosol optical depth, such as polluted urban atmosphere and biomass burning plumes, the error may be even larger due to multiple scattering processes and extend also to trace gases that absorb light in the visible spectral range.
Finally, the potential for OA absorption to affect aerosol broadband solar heating rates is also possible, as shown by the simple calculation in Sect. 3.3, where the inclusion of OA absorption increased the columnar aerosol absorption from $19 \mathrm{~W} / \mathrm{m}^{2}$ to $27 \mathrm{~W} / \mathrm{m}^{2}$. This effect may need to be considered in estimates of the effect of aerosols in so-called "aerosol hot spots" (Ramanathan et al., 2007; Seinfeld, 2008); in these areas, increased absorption by OA may have important implications for atmospheric stability and vertical motion, precipitation patterns, and the amount of radiation reaching the ground.

These conclusions could be validated by performing similar experiments using more sophisticated instruments to measure aerosol absorption, such as a photoacoustic spectrometers (Lack et al., 2008; Lewis et al., 2008; Arnott et al., 1999), which are capable of making these measurements in the nearUV and visible regions. Then it might be possible to determine the MAC - in situ - with greater accuracy, as well as determine if OA contributes significantly to the absorption in the visible wavelength region. If this is indeed the case, then OA absorption probably should be included in aerosol forcing studies related to climate. (However, one again faces the dilemma of assessing the value of a presumably more accurate surface point measurement versus a presumably less accurate, but more relevant, columnar measurement.)

Acknowledgements. This research was sponsored by the US Department of Energy's Atmospheric Science Program (ASP) under Contract DE-AC06-76RLO 1830 at Pacific Northwest National Laboratory. The Pacific Northwest National Laboratory is operated by Battelle for the US Department of Energy. Rainer Volkamer acknowledges Alexander von Humboldt Foundation for a Feodor Lynen Fellowship. Rainer Volkamer thanks Ulrich Platt for making the spectroradiometer available, and Birger Bohn, Claudia Hak, and Jens Bossmeyer for their help with calibrating the instrument at Forschungzentrum Jülich, Germany. The authors wish to thank Beat Schmid for his comments regarding this work, Christian Goering for his retrieved optical thicknesses and single scattering albedos from the UV-MFRSR, and Nancy Marley and Jeff Gaffney for the BC measurements. Finally, we thank Nancy Burleigh for her fine editorial job, catching "typos", etc., that we could never find on our own.

Edited by: T. Kirchstetter

\section{References}

Alexander, D. T. L., Crozier, P. A., and Anderson, J. R.: Brown carbon spheres in East Asian outflow and their optical properties, Science, 321, 833-835, 2008.

Alexandrov, M. D., Kiedron, P., Michalsky, J. J., Hodges, G., Flynn, C. J., and Lacis, A. A.: Optical depth measurements by shadowband radiometers and their uncertainties, Appl. Optics, 46(33), 8027-8038, 2007.

Alfaro, S. C., Lafon. S., Rajot, J. L, Formenti, P., Gaudichet, A., and Maillé, M.: Iron oxides and light absorption by pure desert dust: An experimental study, J. Geophys. Res., 109, D08208, doi:1010.29/2003JD004374, 2004. 
Andreae, M. O. and Gelencsér, A.: Black carbon or brown carbon? The nature of light-absorbing carbonaceous aerosols, Atmos. Chem. Phys., 6, 3131-3148, 2006, http://www.atmos-chem-phys.net/6/3131/2006/.

Arnott, W. P., Moosmuller, H., Rogers, C. F., Jin, T., and Bruch, R.: Photoacoustic spectrometer for measuring light absorption by aerosols: Instrument description, Atmos. Environ., 33, 28452852, 1999.

Barnard, J. C., Kassianov, E. I., Ackerman, T. P., Frey, S., Johnson, K., Zuberi, B., Molina, L. T., Molina, M. J., Gaffney, J. S., and Marley, N. A.: Measurements of Black Carbon Specific Absorption in the Mexico City Metropolitan Area during the MCMA 2003 Field Campaign, Atmos. Chem. Phys. Discuss., 5, 40834113, 2005,

http://www.atmos-chem-phys-discuss.net/5/4083/2005/.

Beirle, S., Platt, U., Wenig, M., and Wagner, T.: Highly resolved global distribution of tropospheric $\mathrm{NO}_{2}$ using GOME narrow swath mode data, Atmos. Chem. Phys., 4, 1913-1924, 2004, http://www.atmos-chem-phys.net/4/1913/2004/.

Bergstrom, R. W., Russell, P. B., and Hignett, P.: Wavelength dependence of absorption of black carbon particles: Predictions and results from the TARFOX experiment and implications for the aerosol single scattering albedo, J. Atmos. Sci., 59, 567-577, 2002.

Bergstrom, R. W., Pilewskie, P., Russell, P. B., Redemann, J., Bond, T. C., Quinn, P. K., and Sierau, B.: Spectral absorption properties of atmospheric aerosols, Atmos. Chem. Phys., 7, 5937-5943, 2007, http://www.atmos-chem-phys.net/7/5937/2007/.

Bohren, C. F. and Huffman, D. R.: Absorption and Scattering of Light by Small Particles, John Wiley \& Sons, New York, USA, 544 pp., 1983.

Bond, T. C., Bussemer, M., Wehner, B., Keller, S., Charlson, R. J., and Heintzenberg, J.: Light absorption by primary particle emissions from a lignite burning plant, Environ. Sci. Technol., 33, 3887-3891, 1999.

Bond, T. C. and Bergstrom, R. W.: Light absorption by carbonaceous particles: An investigative review, Aerosol Sci. Technol., 40, 27-67, 2006.

Bond, T. C., Habib, G., and Bergstrom, R. W.: Limitations in the enhancement of visible light absorption due to mixing state, J. Geophys. Res., 111, D20211, doi:10.1209/2006JD007315, 2006.

Cappa, C., Lack, D. A., Burkholder, J. B., and Ravishankara, A. R.: Bias in filter-based aerosol absorption measurements due to organic aerosol loading: Evidence from laboratory measurements, Aerosol Sci. Tech., 42(12), 1022-1032, 2008.

Castro, T., Ruiz-Suarez, L. G., Ruiz-Suarez, J. C., Molina, M. J., and Montero, M.: Sensitivity analysis of a UV radiation transfer model and experimental photolysis rates of $\mathrm{NO}_{2}$ in the atmosphere of Mexico City, Atmos. Environ., 31, 609-620, 1997.

Castro, T., Madronich, S., Rivale, S., Muhlia, A., and Mar, B.: The influence of aerosols on photochemical smog in Mexico City, Atmos. Environ., 35, 1765-1772, 2001.

Cede, A., Herman, J., Richter, A., Krotkov, N., and Burrows, J.: Measurements of nitrogen dioxide total column amounts using a Brewer double spectrometer in direct Sun mode, J. Geophys. Res., 111, D05304, doi:10.1029/2005JD006585, 2006.

Clarke, A., McNaughton, C., Kapustin, V., Shinozuka, Y., Howell, S., Dibb, J., Zhou, J., Anderson, B., Brekhovskikh, V., Turner, H., and Pinkerton, M.: Biomass burning and pollution aerosol over North America: Organic components and their influence on spectral optical properties and humidification response, J. Geophys. Res., 112, D12S18, doi:10.1029/2006JD007777, 2007.

Coddington, O., Schmidt, K. S., Pilewskie, P., Gore, W. J., Bergstrom, R. W., Román, M. O., Redemann, J., Russell, P. B., Liu, J., and Schaaf, C. B.: Aircraft measurements of spectral surface albedo and its consistency with ground-based and space-borne observations, J. Geophys. Res., 113, D17209, doi:10.1029/2008JD010089, 2008.

de Foy, B., Varela, J. R., Molina, L. T., and Molina, M. J.: Rapid ventilation of the Mexico City basin and regional fate of the urban plume, Atmos. Chem. Phys., 6, 2321-2335, 2006, http://www.atmos-chem-phys.net/6/2321/2006/.

de Foy, B., Lei, W., Zavala, M., Volkamer, R., Samuelsson, J., Mellqvist, J., Galle, B., Martínez, A.-P., Grutter, M., Retama, A., and Molina, L. T.: Modelling constraints on the emission inventory and on vertical dispersion for $\mathrm{CO}$ and $\mathrm{SO}_{2}$ in the Mexico City Metropolitan Area using Solar FTIR and zenith sky UV spectroscopy, Atmos. Chem. Phys., 7, 781-801, 2007,

http://www.atmos-chem-phys.net/7/781/2007/.

Denkenberger, K. A., Moffet, R. C., Holecek, J. C., Rebotier, T. P., and Prather, K. A.: Real-time, single-particle measurements of oligomers in aged ambient aerosol particles, Environ. Sci. Technol., 41, 5439-5446, 2007.

Doran, J. C., Barnard, J. C., Arnott, W. P., Cary, R., Coulter, R., Fast, J. D., Kassianov, E. I., Kleinman, L., Laulainen, N. S., Martin, T., Paredes-Miranda, G., Pekour, M. S., Shaw, W. J., Smith, D. F., Springston, S. R., and Yu, X.-Y.: The T1-T2 study: evolution of aerosol properties downwind of Mexico City, Atmos. Chem. Phys., 7, 1585-1598, 2007,

http://www.atmos-chem-phys.net/7/1585/2007/.

Doran, J. C., Fast, J. D., Barnard, J. C., Laskin, A., Desyaterik, Y., and Gilles, M. K.: Applications of lagrangian dispersion modeling to the analysis of changes in the specific absorption of elemental carbon, Atmos. Chem. Phys., 8, 1377-1389, 2008, http://www.atmos-chem-phys.net/8/1377/2008/.

Dubovik, O., Holben, B., Eck, T. F., Smirnov, A., Kaufman, Y. J., King, M. D., Tanré, D., and Slutsker, I.: Variability of absorption and optical properties of key aerosol types observed in worldwide locations, J. Atmos. Sci., 59, 590-608, 2002.

Fast, J. D., de Foy, B., Acevedo Rosas, F., Caetano, E., Carmichael, G., Emmons, L., McKenna, D., Mena, M., Skamarock, W., Tie, X., Coulter, R. L., Barnard, J. C., Wiedinmyer, C., and Madronich, S.: A meteorological overview of the MILAGRO field campaigns, Atmos. Chem. Phys., 7, 2233-2257, 2007, http://www.atmos-chem-phys.net/7/2233/2007/.

Fuller, K. A., Malm, W. C., and Kreidenweis, S. M.: Effects of mixing on extinction by carbonaceous particles, J. Geophys. Res., 104(D13), 15 941-15 954, 1999.

Goering, C. D., L'Ecuyer, T. S., Stephens, G. L., Slusser, J. R., Scott, G., Davis, J., Barnard, J. C., and Madronich, S.: Simultaneous retrievals of column ozone and aerosol optical properties from direct and diffuse solar irradiance measurements, J. Geophys. Res., 110, D05204, doi:10.1029/2004JD005330, 2005.

Goody, R. M. and Yung, Y. L.: Atmospheric Radiation Theoretical Basis, Second Edition, Oxford University Press, Oxford, UK, 519 pp., 1989.

Hansen, A. D. A., Rosen, H., and Novakov, T.: The aethalometer An instrument for the real-time measurement of optical absorp- 
tion by aerosol particles, Sci. Total Environ., 36, 191-196, 1984. Harrison, L., Michalsky, J., and Berndt, J.: Automated multifilter rotating shadow-band radiometer: an instrument for optical depth and radiation measurements, Appl. Optics, 33, 5118-5125, 1994.

Heue, K.-P., Richter, A., Bruns, M., Burrows, J. P., v. Friedeburg, C., Platt, U., Pundt, I., Wang, P., and Wagner, T.: Validation of SCIAMACHY tropospheric $\mathrm{NO}_{2}$-columns with AMAXDOAS measurements, Atmos. Chem. Phys., 5, 1039-1051, 2005, http://www.atmos-chem-phys.net/5/1039/2005/.

Hoffer, A., Gelencsér, A., Guyon, P., Kiss, G., Schmid, O., Frank, G. P., Artaxo, P., and Andreae, M. O.: Optical properties of humic-like substances (HULIS) in biomass-burning aerosols, Atmos. Chem. Phys., 6, 3563-3570, 2006,

http://www.atmos-chem-phys.net/6/3563/2006/.

IPCC: The physical basis of climate change: Changes in atmospheric constituents and in radiative forcing, 2007.

Jacobson, M. Z.: Isolating nitrated and aromatic aerosols and nitrated aromatic gases as sources of ultraviolet light absorption, J. Geophys. Res., 104(D3), 3527-3542, 1999.

Jayne, J. T., Leard, D. C., Zhang, X., Davidovits, P., Smith, K. A., Kolb, C. E., and Worsnop, D. R.: Development of an Aerosol Mass Spectrometer for size and composition analysis of submicron particles, Aerosol Sci. Tech., 33, 49-70, 2000.

Jeong, C.-H., Hopke, P. K., Kim, E., and Lee, D.-W.: The comparison between thermal - optical transmittance elemental carbon and Aethalometer black carbon measured and multiple monitoring sites, Atmos. Environ., 38, 5193-5204, 2004.

Jimenez, J. L., Jayne, J. T., Shi, Q., Kolb, C. E., Worsnop, D. R., Yourshaw, I., Seinfeld, J. H., Flagan, R. C., Zhang, X., Smith, K. A., Morris, J., and Davidovits, P.: Ambient aerosol sampling using Aerodyne Aerosol Mass Spectrometer, J. Geophys. Res., 108, 8425, doi:10.1029/2001JD001213, 2003.

Johnson, K. S., Zuberi, B., Molina, L. T., Molina, M. J., Iedema, M. J., Cowin, J. P., Gaspar, D. J., Wang, C., and Laskin, A.: Processing of soot in an urban environment: case study from the Mexico City Metropolitan Area, Atmos. Chem. Phys., 5, 30333043, 2005, http://www.atmos-chem-phys.net/5/3033/2005/.

Kassianov, E. I., Flynn, C. J., Ackerman, T. P., and Barnard, J. C.: Aerosol single-scattering albedo and asymmetry parameter from MFRSR observations during the ARM Aerosol IOP 2003, Atmos. Chem. Phys., 7, 3341-3351, 2007,

http://www.atmos-chem-phys.net/7/3341/2007/.

Kirchstetter, T. W., Novakov, T., and Hobbs, P.: Evidence that the spectral dependence of light absorption by aerosols is affected by organic carbon, J. Geophys. Res., 109, D21208, doi:10.1029/2004JD004999, 2004.

Kirchstetter, T. W. and Novakov, T.: Controlled generation of black carbon particles from a diffusion flame and applications in evaluating black carbon, Atmos. Environ., 41(9), 1874-1888, doi:10.1016/j.atmosenv.2006.10.067, 2007.

Kraus, A., and Hofzumahaus, A.: Field measurements of atmospheric photolysis frequencies for $\mathrm{O}_{3}, \mathrm{NO}_{2}, \mathrm{HCHO}, \mathrm{CH}_{3} \mathrm{CHO}$, $\mathrm{H}_{2} \mathrm{O}_{2}$, and $\mathrm{HONO}$ by UV spectroradiometry, J. Atmos. Chem., 31, 161-180, 1998.

Kraus, A., Rohrer, F., and Hofzumahaus, A.: Intercomparison of $\mathrm{NO} 2$ photolysis frequency measurements by actinic flux spectroradiometry and chemical actinometry during JCOM97, Geophys. Res. Lett., 27, 1115-1118, 2000.
Krotkov, N., Bharta, P. K., Herman, J., Slusse, J., Scott, G., Labow, G., Vasilkov, A. P., Eck, T. F., Dubovik, O., and Holben, B. N.: Aerosol ultraviolet absorption experiment (2002 to 2004), part 2: absorption optical thickness, refractive index, and single scattering albedo, Opt. Eng., 44(4), 041005, doi:10.1117/12.638983, 2005.

Lack, D. A., Cappa, C. D., Baynard, T., Massoli, P., Covert, D. S., Sierau, B., Bates, T. S., Quinn, P. K., Lovejoy, E. R., and Ravishankara, A. R.: Bias in filter-based aerosol absorption measurements due to organic aerosol loading: Evidence from ambient sampling, Aerosol Sci. Tech., 42(12), 1033-1041, 2008.

Lei, W., de Foy, B., Zavala, M., Volkamer, R., and Molina, L. T.: Characterizing ozone production in the Mexico City Metropolitan Area: a case study using a chemical transport model, Atmos. Chem. Phys., 7, 1347-1366, 2007,

http://www.atmos-chem-phys.net/7/1347/2007/.

Lewis, K., Arnott, W. P., Moosmüller, H., and Wold, C. E.: Strong spectral variation of wood smoke light absorption and single scattering albedo observed in-situ using a novel dual wavelength photoacoustic instrument, J. Geophys. Res, 113, D16203, doi:10.1029/2007JD009699, 2008.

Linke, C., Möhler, O., Veres, A., Mohácsi, Á., Bozóki, Z., Szabó, G., and Schnaiter, M.: Optical properties and mineralogical composition of different Saharan mineral dust samples: a laboratory study, Atmos. Chem. Phys., 6, 3315-3323, 2006, http://www.atmos-chem-phys.net/6/3315/2006/.

Long, C. N. and Ackerman, T. P.: Identification of clear skies from broadband pyranometer measurements and calculation of downwelling shortwave cloud effects, J. Geophys. Res., 105(D12), 15 609-15 626, 2000.

Michalsky, J. J., Schlemmer, J. A., Berkheiser, W. E., Berndt, J. L., Harrison, L. C., Laulainen, N. S., Larson, N. R., and Barnard, J. C.: Multi-year measurements of aerosol optical depth in the atmospheric radiation measurement and quantitative links programs, J. Geophys. Res., 106(D11), 12 099-12 107, 2001.

Michalsky, J. J. and Kiedron, P. W.: Comparison of UV-RSS spectral measurements and TUV model runs for clear skies for the May 2003 ARM aerosol intensive observation period, Atmos. Chem. Phys., 8, 1813-1821, 2008,

http://www.atmos-chem-phys.net/8/1813/2008/.

Molina, L. T., Kolb, C. E., de Foy, B., Lamb, B. K., Brune, W. H., Jimenez, J. L., Ramos-Villegas, R., Sarmiento, J., ParamoFigueroa, V. H., Cardenas, B., Gutierrez-Avedoy, V., and Molina, M. J.: Air quality in North America's most populous city overview of the MCMA-2003 campaign, Atmos. Chem. Phys., 7, 2447-2473, 2007, http://www.atmos-chem-phys.net/7/2447/2007/.

Ramanathan, V., Li, F., Ramana, M. V., Praveen, P. S., Kim, D., Corrigan, C. E., Nguyen, H., Stone, E. A., Schauer, J. J., Carmichael, G. R., Adhikary, B., and Yoon, S. C.: Atmospheric brown clouds: Hemispherical and regional variations in longrange transport, absorption, and radiative forcing, J. Geophys. Res., 112, D22S21, doi:10.1029/2006JD008124, 2007.

Ricchiazzi, P., Yang, S., Gautier, C., and Sowle, D.: SBDART: A research and teaching software tool for plane-parallel radiative transfer in the Earth's atmosphere, B. Am. Meteorol. Soc., 79(10), 2101-2114, 1998.

Roden, C. A., Bond, T. C., Conway, S., and Pinel, A. B. O.: Emission factors and real-time optical properties for particles emitted 
from traditional wood burning cook stoves, Environ. Sci. Technol., 40, 6750-6757, 2006.

Salcedo, D., Onasch, T. B., Dzepina, K., Canagaratna, M. R., Zhang, Q., Huffman, J. A., DeCarlo, P. F., Jayne, J. T., Mortimer, P., Worsnop, D. R., Kolb, C. E., Johnson, K. S., Zuberi, B., Marr, L. C., Volkamer, R., Molina, L. T., Molina, M. J., Cardenas, B., Bernab, R. M., Márquez, C., Gaffney, J. S., Marley, N. A., Laskin, A., Shutthanandan, V., Xie, Y., Brune, W., Lesher, R., Shirley, T., and Jimenez, J. L.: Characterization of ambient aerosols in Mexico City during the MCMA-2003 campaign with Aerosol Mass Spectrometry: results from the CENICA Supersite, Atmos. Chem. Phys., 6, 925-946, 2006,

http://www.atmos-chem-phys.net/6/925/2006/.

San Martini, F. M., Dunlea, E. J., Volkamer, R., Onasch, T. B., Jayne, J. T., Canagaratna, M. R., Worsnop, D. R., Kolb, C. E., Shorter, J. H., Herndon, S. C., Zahniser, M. S., Salcedo, D., Dzepina, K., Jimenez, J. L., Ortega, J. M., Johnson, K. S., McRae, G. J., Molina, L. T., and Molina, M. J.: Implementation of a Markov Chain Monte Carlo method to inorganic aerosol modeling of observations from the MCMA-2003 campaign Part II: Model application to the CENICA, Pedregal and Santa Ana sites, Atmos. Chem. Phys., 6, 4889-4904, 2006, http://www.atmos-chem-phys.net/6/4889/2006/.

Schnaiter, M., Gimmler, M., Llamas, I., Linke, C., Jäger, C., and Mutschke, H.: Strong spectral dependence of light absorption by organic carbon particles formed by propane combustion, Atmos. Chem. Phys., 6, 2981-2990, 2006, http://www.atmos-chem-phys.net/6/2981/2006/.

Schuster, G. L., Dubovik, O., Holben, B. N., and Clothiaux, E. E.: Inferring the black carbon content and specific absorption from AERONET retrievals, J. Geophys. Res., 101, D10S17, doi:10.1029/2004JD004548, 2005.

Seinfeld, J. H.: Black carbon and brown clouds, Nature Geoscience, 1, 15, 2008.

Singh, H. B., Brune, W. H., Crawford, J. H., Jacob, D. J., and Russell, P. B.: Overview of the summer 2004 Intercontinental Chemical Transport Experiment - North America (INTEX A), J. Geophys. Res., 111, D24S01, doi:10.1029/2006JD007905, 2006.
Sokolik, I. N. and Toon, O. B.: Incorporation of mineralogical composition of aerosols into models of radiative properties of mineral aerosol from the UV to IR wavelengths, J. Geophys. Res., 104(D8), 9423-9444, 1999.

Subramanian, R., Roden, C. A., Boparai, P., and Bond, T. C.: Yellow beads and missing particles: Trouble ahead for filter-based absorption measurements, Aerosol Sci. Tech. 41, 630-637, 2007.

Sun, H., Biedermann, L., and Bond, T. C.: The color of brown carbon: A model for ultraviolet and visible light absorption by organic carbon aerosol, Geophys. Res. Lett., 34, L17813, doi:10.1029/2007GL029797, 2007.

Turpin, B. J. and Lim, H.-J.: Species contributions to $\mathrm{PM}_{2.5}$ mass concentrations: Revisiting common assumptions for estimating organic mass, Aerosol Sci. Tech., 35, 602-610, 2001.

Wagner, F. and Silva, A. M.: Some considerations about Ångström exponent distributions, Atmos. Chem. Phys., 8, 481-489, 2008, http://www.atmos-chem-phys.net/8/481/2008/.

Wenny, B. N., Schafer, J. S., DeLuisi, J. J., Saxena, V. K., Barnard, W. F., Petropavlovskikh, I. V., and Vergamini, A. J.: A study of regional radiative properties and effects on ultraviolet-B radiation, J. Geophys. Res., 103(D14), 18083-17097, 1998.

Volkamer, R., Molina, L. T., Molina, M. J., Shirley, T., and Brune, W. H.: DOAS measurement of glyoxal as an indicator for fast VOC chemistry in urban air, Geophys. Res. Lett., 32, L08806, doi:10.1029/2005GL022616, 2005.

Volkamer, R., Jimenez, J. L., San Martini, F., Dzepina, K., Zhang, Q., Salcedo, D., Molina, L. T., Worsnop, D. R., and Molina, M. J.: Secondary organic aerosol formation from anthropogenic air pollution: Rapid and higher than expected, Geophys. Res. Lett., 33, L17811, doi:10.1029/2006GL026899, 2006.

Volkamer, R., San Martini, F., Salcedo, D., Molina, L. T., Jimenez, J. L., and Molina, M. J.: A missing sink for gas-phase gloxal in Mexico City: Formation of secondary organic aerosol, Geophys. Res. Lett., 34, L19807, doi:10.1029/2007GL030752, 2007a.

Volkamer, R., Sheehy, P. M., Molina, L. T., and Molina, M. J.: Oxidative capacity of the Mexico City atmosphere Part 1: A radical source perspective, Atmos. Chem. Phys. Discuss., 7, 5365-5412, 2007, http://www.atmos-chem-phys-discuss.net/7/5365/2007/. 